\title{
Apolipoprotein E, Especially Apolipoprotein E4, Increases the Oligomerization of Amyloid $\beta$ Peptide
}

\author{
Tadafumi Hashimoto, ${ }^{1}$ Alberto Serrano-Pozo, ${ }^{1}$ Yukiko Hori, ${ }^{1}$ Kenneth W. Adams, ${ }^{1}$ Shuko Takeda, ${ }^{1}$ \\ Adrian Olaf Banerji, ${ }^{1}$ Akinori Mitani, ${ }^{1}$ Daniel Joyner, ${ }^{1}$ Diana H. Thyssen, ${ }^{1}$ Brian J. Bacskai, ${ }^{1}$ Matthew P. Frosch, ${ }^{1}$ \\ Tara L. Spires-Jones, ${ }^{1}$ Mary Beth Finn, ${ }^{2}$ David M. Holtzman, ${ }^{2}$ and Bradley T. Hyman ${ }^{1}$ \\ ${ }^{1}$ Department of Neurology, Alzheimer's Disease Research Unit, Massachusetts General Hospital, Charlestown, Massachusetts 02129, and ${ }^{2}$ Department of \\ Neurology, Hope Center for Neurological Disorders, Knight Alzheimer's Disease Research Center, Washington University School of Medicine, St. Louis, \\ Missouri 63110
}

\begin{abstract}
Alzheimer's disease (AD) is the most common progressive neurodegenerative disorder causing dementia. Massive deposition of amyloid $\beta$ peptide $(\mathrm{A} \beta)$ as senile plaques in the brain is the pathological hallmark of $\mathrm{AD}$, but oligomeric, soluble forms of $\mathrm{A} \beta$ have been implicated as the synaptotoxic component. The apolipoprotein $\mathrm{E} \varepsilon 4(\mathrm{apoE} \varepsilon 4)$ allele is known to be a genetic risk factor for developing AD. However, it is still unknown how apoE impacts the process of $\mathrm{A} \beta$ oligomerization. Here, we found that the level of $\mathrm{A} \beta$ oligomers in $A P O E \varepsilon 4 / \varepsilon 4 \mathrm{AD}$ patient brains is 2.7 times higher than those in $A P O E \varepsilon 3 / \varepsilon 3 \mathrm{AD}$ patient brains, matched for total plaque burden, suggesting that apoE4 impacts the metabolism of $\mathrm{A} \beta$ oligomers. To test this hypothesis, we examined the effect of apoE on $\mathrm{A} \beta$ oligomer formation. Using both synthetic $A \beta$ and a split-luciferase method for monitoring $A \beta$ oligomers, we observed that apoE increased the level of $A \beta$ oligomers in an isoform-dependent manner $(\mathrm{E} 2<\mathrm{E} 3<\mathrm{E} 4)$. This effect appears to be dependent on the ApoE C-terminal domain. Moreover, these results were confirmed using endogenous apoE isolated from the TBS-soluble fraction of human brain, which increased the formation of $\mathrm{A} \beta$ oligomers. Together, these data show that lipidated apoE, especially apoE4, increases $\mathrm{A} \beta$ oligomers in the brain. Higher levels of $\mathrm{A} \beta$ oligomers in the brains of $A P O E \varepsilon 4 / \varepsilon 4$ carriers compared with $A P O E \varepsilon 3 / \varepsilon 3$ carriers may increase the loss of dendritic spines and accelerate memory impairments, leading to earlier cognitive decline in $\mathrm{AD}$.
\end{abstract}

\section{Introduction}

The hallmark of Alzheimer's disease (AD) is deposition of fibrillar amyloid $\beta$ peptide $(\mathrm{A} \beta)$ in senile plaques in the brain (Selkoe, 2001; Holtzman et al., 2011). Recent data, however, suggest that instead of, or in addition to, plaques, soluble oligomeric forms of $\mathrm{A} \beta$ are crucial for synaptic dysfunction, cognitive impairment and neurodegeneration (Lesné et al., 2006; Shankar et al., 2008; Koffie et al., 2009; Wu et al., 2010). However, it is still unknown what factors influence the kinetics of formation of soluble $\mathrm{A} \beta$ oligomers.

Apolipoprotein $\mathrm{E}$ (apoE) is a known $\mathrm{A} \beta$ binding protein and is a genetic risk factor for $\mathrm{AD}(\mathrm{Bu}, 2009)$. There are 3 common alleles of the human $A P O E$ gene $\varepsilon 2, \varepsilon 3$, and $\varepsilon 4$ (Zannis et al., 1982). Inheritance of two copies of the $A P O E \varepsilon 4$ allele is associ-

\footnotetext{
Received March 29, 2012; revised June 16, 2012; accepted July 13, 2012.

Author contributions: T.H., K.W.A., B.J.B., M.P.F., T.L.S.-J., and B.T.H. designed research; T.H., A.S.-P., Y.H., S.T., A.O.B., A.M., D.J., and D.H.T. performed research; M.B.F. and D.M.H. contributed unpublished reagents/analytic tools; T.H., A.S.-P., M.P.F., and B.T.H. analyzed data; T.H., A.S.-P., and B.T.H. wrote the paper.

This work was supported by NIH Grants AG12406 (B.T.H.), AG13956 (D.M.H.), and AG033670 (T.L.S.-J.), Ellison Medical Foundation/AFAR Grant 2009A059868 (T.H.), Fundación Alfonso Martín Escudero (A.S.-P.), and P50 AG005134 (Massachusetts Alzheimer's Disease Research (enter). We thank Drs. Zhanyun Fan and Pamela J. McLean for the construction of split-luciferase-tagged A $\beta$ cDNA plasmids. We also thank Dr. Eloise Hudry and Dr. Robert M. Koffie for valuable discussion.

Correspondence should be addressed to Bradley T. Hyman, Department of Neurology, Alzheimer's Disease Research Unit, Massachusetts General Hospital, Building 114, 16th Street, Charlestown, MA 02129. E-mail: bhyman@partners.org.

DOI:10.1523/JNEUROSCI.1542-12.2012

Copyright $\odot 2012$ the authors $\quad 0270-6474 / 12 / 3215181-12 \$ 15.00 / 0$
}

ated with a $>10$-fold increased risk for developing $\mathrm{AD}$ compared with the most common $A P O E \varepsilon 3 / \varepsilon 3$ genotype (Corder et al., 1993; Strittmatter et al., 1993a). However, the mechanisms whereby $A P O E \varepsilon 4$ promotes the development of $\mathrm{AD}$ remain controversial. There is strong evidence that apoE, and particularly apoE4, facilitates amyloid fibril deposition. Senile plaque density in the brains of $A P O E \varepsilon 4 / \varepsilon 4$ carrier $\mathrm{AD}$ patients is significantly higher than that in the brains of $A P O E \varepsilon 3 / \varepsilon 3$ carrier $A D$ patients (Rebeck et al., 1993; Gomez-Isla et al., 1996). apoE-deficient mice crossed with APP (amyloid precursor protein)-transgenic mice exhibited a decrease in amyloid deposition in the brain, and human apoE4 overexpression increased fibrillar $A \beta$ deposits compared with human apoE3 (Holtzman et al., 2000; Fagan et al., 2002). Moreover, recent studies support a role of apoE in $A \beta$ metabolism. Using an in vivo microdialysis technique, the halflife of $\mathrm{A} \beta$ in the brain of apoE knock-out mice markedly decreased compared with wild-type mice (DeMattos et al., 2004). Importantly, it has now been shown that in APP-transgenic mice expressing apoE2, E3, and E4, apoE4 significantly slows $\mathrm{A} \beta$ clearance relative to $\mathrm{E} 2$ and $\mathrm{E} 3$ but has no effect on $\mathrm{A} \beta$ synthesis (Castellano et al., 2011).

Previous studies have revealed that apoE interacts with $\mathrm{A} \beta$ in vitro (Strittmatter et al., 1993b; LaDu et al., 1994) and in vivo, both in the CSF (Strittmatter et al., 1993a) and in the brain (Näslund et al., 1995). However, because of the difficulty in monitoring $A \beta$ oligomers specifically and quantitatively, whether apoE increases the levels of native $\mathrm{A} \beta$ oligomers remains unknown. In 
this study we hypothesize that apoE, especially apoE4, impacts the formation of $A \beta$ oligomers. We observed significantly increased levels of $A \beta$ oligomers in APOE $\varepsilon 4 / \varepsilon 4$ AD patient brains compared with APOE $\varepsilon 2 / \varepsilon x$ or APOE $\varepsilon 3 / \varepsilon 3$ AD patient brains. We also found that apoE4 enhances the level of $A \beta$ oligomers, using a split-luciferase complementation assay that enables quantitative monitoring of the formation of $\mathrm{A} \beta$ oligomers. Furthermore, endogenous apoE from human brain also increased the level of $\mathrm{A} \beta$ oligomers in vitro. These data suggest that apoE, especially apoE4, impacts $\mathrm{A} \beta$ oligomer levels by enhancing their formation and stabilizing them once formed.

\section{Materials and Methods}

Brain extraction and gel filtration. Brains from human subjects with a diagnosis of Alzheimer's disease or no cognitive deficits were obtained through the Massachusetts Alzheimer's Disease Research Center. Cases were selected to have equivalent amyloid load (Ingelsson et al., 2004) and to be either $A P O E \varepsilon 2 / \varepsilon x, A P O E \varepsilon 3 / \varepsilon 3$, or $A P O E \varepsilon 4 / \varepsilon 4$; these data were not revealed during subsequent biochemical assays. The case number is 8 in control ( 4 males and 4 females), 6 in $A P O E \varepsilon 2 / \varepsilon x \mathrm{AD}$ ( 6 females), 10 in APOE $\varepsilon 3 / \varepsilon 3 \mathrm{AD}$ (4 males and 6 females) or 10 in APOE $\varepsilon 4 / \varepsilon 4 \mathrm{AD}(5$ males and 5 females). Cortical gray matter from frontal lobe of AD patient brains or non-demented control brains was homogenized in 5 volumes of TBSI (Tris-buffered saline with Protease Inhibitor Cocktail; Roche) with 25 strokes on a mechanical Dounce homogenizer and centrifuged at $260,000 \times g$ for $30 \mathrm{~min}$ at $4^{\circ} \mathrm{C}$. The supernatant was used as a TBS-soluble fraction (Hashimoto et al., 2002). TBS-soluble fraction (750 $\mu l$ ) of human brains was separated by size-exclusion chromatography (SEC) on single or double Superdex 75 columns (GE Healthcare) in 50 mM ammonium acetate, $\mathrm{pH} 8.5$, with an AKTA purifier 10 (GE Healthcare; Townsend et al., 2006). Conditioned medium from HEK293 cells $(750 \mu \mathrm{l})$ was separated by size exclusion chromatography on a Superdex 200 column (GE Healthcare) in $50 \mathrm{~mm}$ ammonium acetate, $\mathrm{pH} 8.5$, with an AKTA purifier 10 (GE Healthcare). The individual fractions separated by SEC were analyzed by immunoblotting and $A \beta$-specific sandwich ELISA.

cDNA plasmids. Human ApoE2, ApoE3, and ApoE4 genes were a gift from Dr. Mary Jo LaDu at University of Illinois at Chicago. The human ApoA-I gene was purchased from the full-length mammalian gene collection (Invitrogen) and subcloned into pcDNA3.1 vector (Invitrogen) between HindIII site and BamHI site using the following primers: $5^{\prime}-\mathrm{GA}$ GAAGAAGCTTCCCCACGGCCCTTCAGG-3' (forward), 5'-ATTC TGGGATCCGGGAAGGGGGGCGGCGG-3' (reverse). The human ApoA-II gene was also purchased from the full-length mammalian gene collection and subcloned into pcDNA3.1 vector between HindIII site and BamHI site using the following primers: $5^{\prime}$-ACAGAGAAGCTTGCTA GGCCGCCCTCCCC-3' (forward), 5' -GGGACAGGATCCCTAGGACT GGCCAGTGGG-3' (reverse). The human ApoJ/clusterin gene was purchased from the full-length mammalian gene collection and subcloned into pcDNA3.1 vector between HindIII site and BamHI site using the following primers: $5^{\prime}$-TGACCGAAGCTTGCAAAGACTCCAGAAT TGG-3' (forward), 5'-AGTGCAGGATCCAGAGCGGGGAGAGG-3' (reverse). For the apoE4 R61T mutant, we mutated Arg61 of apoE4 cDNA plasmid into Thr by in vitro site-directed mutagenesis using the following primers: 5'-CACCCAGGAGCTCACGGCGCTGATGG-3' (forward), 5'-CCATCAGCGCCGTGAGCTCCTGGGTG-3' (reverse). For the N-terminal fragments of apoE (apoE2 NTF, apoE3 NTF, and apoE4 NTF), we deleted apoE192-299 from the apoE2, apoE3, and apoE4 cDNA plasmids, respectively, using the following primers: $5^{\prime}-\mathrm{TG}$ AACGCCGAAGCCTGCAGCCATGCG-3' (apoE1-191 forward), 5' -CC GCACGCGGCCCTGTTCCACCAGGGG-3' (apoE1-191 reverse). For the C-terminal fragment of apoE (apoE CTF), we deleted apoE1-191 from the apoE2 cDNA plasmid using the following primers: $5^{\prime}$-GCCG CCACTGTGGGCTCCCTGGCC-3' (apoE192-299 forward), 5' -CTTG GCCTGGCATCCTGCCAGGAATGTG-3' (apoE192-299 reverse). The apoE signal sequence was retained before the apoE CTF. For the apoE231-299, we deleted apoE192-230 from the apoE CTF cDNA plasmid using the following primers: 5'-GAGGTGAAGGAGCAGGTGGC
GGAGG-3' (apoE231-299 forward) and apoE192-299 reverse primer. For apoE243-299, we deleted apoE192-242 from the apoE CTF cDNA plasmid using the following primers: 5'-CTGGAGGAGCAGGCCCAG CAGATACGCC-3' (apoE243-299 forward) and apoE192-299 reverse primer. For apoE192-272, we deleted apoE273-299 from the apoE CTF CDNA plasmid using the following primers: apoE1-191 forward primer and 5'-CATGTCTTCCACCAGGGGCTCGAACC-3' (apoE192-272 reverse). For apoE192-242, we deleted apoE243-299 from the apoE CTF cDNA plasmid using the following primers: apoE1-191 forward primer and 5'-CTTGGCGCGCACCTCCGCCACCTGC-3' (apoE192-242 reverse). For apoE3 $\Delta 243-272$, we deleted apoE243-272 from the apoE3 cDNA plasmid using the following primers: 5 '-CAGCGCCAGTGGGC CGGGCTGGTGG-3' (apoE273-299 forward) and apoE192-242 reverse primer. For apoE3 $\Delta 273-299$, we deleted apoE273-299 from the apoE3 cDNA plasmid using the following primers: apoE1-191 forward primer and apoE192-272 reverse primer. For apoE3 $\Delta 243-299$, we deleted apoE243-299 from the apoE3 cDNA plasmid using the following primers: apoE1-191 forward primer and apoE192-242 reverse primer.

Cell culture and transient transfection. Both $\mathrm{N}$-terminal and C-terminal fragments of split-luciferase-tagged A $\beta$ stably overexpressing HEK293 cells (doubly expressing HEK293 cells) were generated previously (Hashimoto et al., 2011). Doubly expressing HEK293 cells were cultured in Opti-MEM (Invitrogen) with $10 \%$ fetal bovine serum at $37^{\circ} \mathrm{C}$ in $5 \%$ $\mathrm{CO}_{2}$ atmosphere. Transient apoEs or apoE mutants expressing cell lines were generated by transfecting cDNA plasmids using Lipofectamine 2000 (Invitrogen) as suggested by the manufacturer. For luciferase assays of the conditioned medium, we incubated HEK293 cells $24 \mathrm{~h}$ after transfection, changed the medium to Opti-MEM without fetal bovine serum for $24 \mathrm{~h}$ at $37^{\circ} \mathrm{C}$ in $5 \% \mathrm{CO}_{2}$ atmosphere, and collected conditioned medium. For luciferase assays of the cell lysate, we washed the cells with PBS and harvested them with Lysis Buffer (Promega).

Immunoblotting, sandwich ELISA, immunodepletion, immunoprecipitation. Brain TBS-soluble fractions, individual SEC fractions or conditioned media from HEK293 cells were electrophoresed on $10-20 \%$ or 4-20\% Novex Tris-Glycine gels (Invitrogen) in Tris-Glycine SDS running buffer for SDS-PAGE (Invitrogen). Gels were transferred to a polyvinylidene difluoride membrane (PolyScreen, PerkinElmer), and blocked for $30 \mathrm{~min}$ at room temperature (RT) in 5\% nonfat skim milk/ TBST (Tris-buffer saline with $0.1 \%$ Tween 20). Membranes were probed with $1 \mu \mathrm{g} / \mathrm{ml}$ monoclonal anti-A $\beta$ antibody $6 \mathrm{E} 10$ (Signet) or 82E1 (IBL International), anti-apoE antibody 6C5 (Ottawa Heart Institute), or 3H1 (Ottawa Heart Institute) in TBST for $2 \mathrm{~h}$ at RT or for $12 \mathrm{~h}$ at $4^{\circ} \mathrm{C}$. Following incubation with horseradish peroxidase-conjugated secondary antibody (Bio-Rad) for $1 \mathrm{~h}$ at RT, immunoreactive proteins were developed using an ECL kit (Western Lightning, PerkinElmer) and detected on Hyperfilm ECL (GE Healthcare; Jones et al., 2011). For the $\mathrm{A} \beta 40$ and $\mathrm{A} \beta 42$ quantification, individual SEC fractions were diluted and subjected to BNT77/BA27 for $\mathrm{A} \beta 40$, or BNT77/BC05 for $\mathrm{A} \beta 42$ using two-site ELISAs (WAKO Chemicals) and quantified as suggested by the manufacturer. For guanidine treatment, individual SEC fractions were incubated with $8 \mathrm{M}$ guanidine- $\mathrm{HCl}$ (concentration of guanidine- $\mathrm{HCl}$ in the sample is $4 \mathrm{M}$ ) for $30 \mathrm{~min}$ at room temperature, diluted by 7 volumes of standard dilution buffer (final concentration of guanidine- $\mathrm{HCl}$ in the sample is $0.5 \mathrm{M}$ ) and subjected to ELISA (Yamada et al., 2009). For immunodepletion, we first incubated $200 \mu \mathrm{l}$ of SEC-separated fractions with $30 \mu \mathrm{l}$ of protein $\mathrm{G}$ magnetic beads (Millipore) for $1 \mathrm{~h}$ at $4^{\circ} \mathrm{C}$ and removed beads by using a magnet. We next incubated supernatants with or without $5 \mu \mathrm{g}$ of anti-human apoE $\mathrm{mAb} 3 \mathrm{H} 1$ or anti-ApoA-I mAb $4 \mathrm{H} 1$ (Ottawa Heart Institute) for $12 \mathrm{~h}$ at $4^{\circ} \mathrm{C}$. We further incubated samples with $30 \mu$ l of protein $\mathrm{G}$ magnetic beads for $2 \mathrm{~h}$ at $4^{\circ} \mathrm{C}$, removed beads by using a magnet, and collected the supernatant as immunodepleted samples. For immunoprecipitation, we first incubated $200 \mu$ l of SECseparated fractions with $30 \mu \mathrm{l}$ of protein-G Sepharose beads (Invitrogen) for $1 \mathrm{~h}$ at $4^{\circ} \mathrm{C}$ and removed beads by centrifugation at $8000 \mathrm{rpm}$ for $5 \mathrm{~min}$ at $4^{\circ} \mathrm{C}$. The supernatants were incubated with anti-apoE (Millipore, Calbiochem), anti-A $\beta$ (6E10), or control Ig (anti-p-glycoprotein) for $8 \mathrm{~h}$ at $4^{\circ} \mathrm{C}$. Incubated samples were centrifuged at $8000 \mathrm{rpm}$ for $5 \mathrm{~min}$ at $4^{\circ} \mathrm{C}$ and the pellets were washed by TBST 2 times, incubated with sample buffer for $10 \mathrm{~min}$ at $95^{\circ} \mathrm{C}$, and applied to SDS-polyacrylamide gels. 
Table 1. Information about the cases used in this study

\begin{tabular}{|c|c|c|c|c|c|}
\hline & Number & Age at death (years) & Gender, $n$ ( $\%$ female) & Disease duration (years) & Postmortem interval (hours) \\
\hline Control $^{a}$ & 8 & $77.7 \pm 10.5$ & $4(50.0)$ & NA & $24.3 \pm 22.1$ \\
\hline $\mathrm{AD}(\epsilon 2 / \epsilon \mathrm{X})^{b}$ & 6 & $78.8 \pm 8.7$ & $6(100.0)$ & $11.7 \pm 5.2$ & $20.0 \pm 7.1$ \\
\hline$A D(\epsilon 3 / \epsilon 3)$ & 10 & $78.7 \pm 10.5$ & $6(60.0)$ & $11.7 \pm 4.7$ & $14.7 \pm 8.0$ \\
\hline $\mathrm{AD}(\epsilon 4 / \epsilon 4)$ & 10 & $78.5 \pm 8.0$ & $5(50.0)$ & $13.6 \pm 4.6$ & $19.6 \pm 19.0$ \\
\hline$p$ value $^{c}$ & NA & 0.9977 & 0.8994 & 0.9830 & 0.6968 \\
\hline
\end{tabular}

${ }^{a} 0 f$ these individuals, $n=2(\epsilon 2 / \epsilon 3), n=5(\epsilon 3 / \epsilon 3), n=1(\epsilon 3 / \epsilon 4)$.

${ }^{b} 0$ f these individuals, $n=1(\epsilon 2 / \epsilon 2), n=2(\epsilon 2 / \epsilon 3), n=3(\epsilon 2 / \epsilon 4)$.

'One-way Kruskal-Wallis ANOVA, except for gender, which was analyzed using $\chi^{2}$ test. Postmortem interval was not available for 2 controls and 1 AD $(\epsilon 2 / \epsilon x)$ subject.

NA, Not applicable.

Statistical analysis was performed by one-way ANOVA using Prism 5 for Mac OSX (GraphPad). Following ANOVA, Bonferroni's or Tukey's post hoc test was applied.

$A \beta$ Immunohistochemistry and amyloid burden analysis. Eight-micrometerthick paraffin-embedded sections from the frontal association cortex (Brodmann's area 8,9) were obtained from the Massachusetts General Hospital Alzheimer Disease Research Center Brain Bank. Sections were deparaffinized with xylenes, rinsed in $\mathrm{H}_{2} \mathrm{O}_{2} 0.3 \%$ in methanol for 20 min to block the endogenous peroxidase activity, and hydrated with decreasing concentrations of ethanol. Antigen retrieval before immunostaining was achieved by microwaving the sections in citrate buffer $(0.01 \mathrm{M}$ citric acid anhydrous, Tris-buffered saline, $0.05 \%$ Tween $20, \mathrm{NaOH}$ to $\mathrm{pH} 6.0$ ) at $95^{\circ} \mathrm{C}$ for $20 \mathrm{~min}$, followed by a rinse in formic acid $90 \%$ for $5 \mathrm{~min}$. After extensive washing, sections were blocked with $5 \%$ nonfat milk for $1 \mathrm{~h}$ to avoid nonspecific binding of the primary antibody. Sections were incubated overnight at $4^{\circ} \mathrm{C}$ with the $\mathrm{N}$-terminal-specific anti-A $\beta$ 10D5 mouse monoclonal antibody (1:50, Elan Pharmaceuticals). On the next day, sections were thoroughly washed, incubated with a goat anti-mouse-HRP-linked secondary antibody (1:200, Jackson ImmunoResearch) for $2 \mathrm{~h}$ at room temperature, and developed with 3-3'-diaminobenzidine. Finally, sections were lightly counterstained with Mayer's hematoxylin, dehydrated with increasing concentrations of ethanol, cleared with xylenes, and coverslipped with Permount mounting medium (Fisher Scientific).

The amyloid plaque burden (or amyloid load) was measured as the percentage of total cortical surface occupied by amyloid plaques. Plaque burden analysis was performed using the BIOQUANT system. Briefly, sections were placed on the motorized stage of an upright Leica DMRB microscope that was equipped with a CCD camera (model DC330, DAGE-MT) and coupled with BIOQUANT Nova Prime software (version 6.90.10.MBSR). An $\approx 1$-cm-long strip of full-depth cortex was outlined under the $1.6 \times$ objective and amyloid plaques were thresholded under the $10 \times$ objective using the appropriate tool of the software (Ingelsson et al., 2004).

Purification of apoE from immortalized astrocytes. Lipidated apoE particles were purified from culture media of human apoE2-, apoE3-, or apoE4-overexpressing immortalized astrocytes using an affinity column as described previously (Morikawa et al., 2005). Briefly, astrocytes were cultured in advanced DMEM (Invitrogen) with $10 \%$ FBS. After $90-95 \%$ confluency, cells were washed by PBS and further incubated in advanced DMEM with N-2 Supplement (Invitrogen) and $3 \mathrm{~mm}$ 25-hydroxycholesterol (Sigma) during 2 3 d. Collected culture media were applied onto mouse monoclonal antibody against a human apoE (WU E-4) column. Lipidated apoE particles were eluted from the column with $3 \mathrm{~m}$ sodium thiocyanate, concentrated using Apollo centrifugal quantitative concentrators (QMWL: 150 $\mathrm{kDa}$, Orbital Biosciences), and dialyzed against PBS.

In vitro $A \beta$ oligomerization assay. We incubated $0.1 \mathrm{mg} / \mathrm{ml}$ synthetic $\mathrm{A} \beta 1-42$ (Peptides International) with or without $10 \mu \mathrm{g}$ of purified apoE2, apoE3, or apoE4 particles at $4^{\circ} \mathrm{C}$ for $0,1.5,6,12$, and $24 \mathrm{~h}$ and immediately applied the solution to SDS-PAGE (Hori et al., 2007).

Split-luciferase complementation assay. HEK293 cells were stably transfected with two plasmids, each containing a complementary splitluciferase assay for $A \beta$ oligomerization, as we have recently described (Hashimoto et al., 2011). Conditioned media from these cells were collected and centrifuged at $1200 \mathrm{rpm}$ for $5 \mathrm{~min}$ to remove cell debris. After adding $17 \mu \mathrm{g} / \mathrm{ml}$ coelenterazine (NanoLight Technology) diluted by
Opti-MEM into samples, luciferase activity was immediately measured using a Wallac 1420 (PerkinElmer) plate reader.

Statistical analysis was performed by one-way ANOVA using Prism 5 for Mac OSX (GraphPad). Following ANOVA, Bonferroni's post hoc test is applied.

\section{Results}

\section{$A P O E \varepsilon 4 / \varepsilon 4 \mathrm{AD}$ patients have higher levels of $\mathrm{A} \beta$ oligomers in their brain than do APOE $\varepsilon 3 / \varepsilon 3$ or $A P O E \varepsilon 2 / \varepsilon \times \mathrm{AD}$ patients}

To investigate the effect of the different apoE isoforms on the metabolism of $\mathrm{A} \beta$ oligomers, we extracted the TBS-soluble fraction from the frontal associative neocortices of 8 non-demented controls, $6 \mathrm{AD}$ patients with the APOE $\varepsilon 2 / \varepsilon \mathrm{x}$ genotype, $10 \mathrm{AD}$ patients with the $A P O E \varepsilon 3 / \varepsilon 3$ genotype, and $10 \mathrm{AD}$ patients with the APOE $\varepsilon 4 / \varepsilon 4$ genotype (Table 1 ). Because it is known that the level of senile plaque density in $A P O E \varepsilon 4 / \varepsilon 4$ carrier $\mathrm{AD}$ is on average significantly higher than that in $A P O E \varepsilon 3 / \varepsilon 3$ carrier AD (Rebeck et al., 1993), we carefully selected brains to have equal amyloid load in an adjacent cortical region by an immunohistochemical analysis using anti-A $\beta$ antibody $10 \mathrm{D} 5(3.7 \pm 1.4 \%$ in $A P O E \varepsilon 2 / \varepsilon x \mathrm{AD}$ patients, $3.0 \pm 1.3 \%$ in $A P O E \varepsilon 3 / \varepsilon 3 \mathrm{AD}$ patients and $3.4 \pm 2.1 \%$ in $A P O E \varepsilon 4 / \varepsilon 4 \mathrm{AD}$ patients, no significant difference; Fig. $1 C$ ). Selected brains also had a similar age at death, gender ratio, disease duration, and postmortem interval (Table 1). An equal amount of the TBS-soluble proteins from each of these brains was applied to SDS-polyacrylamide gels and visualized by anti-human $\mathrm{A} \beta$-specific antibody $82 \mathrm{E} 1$ (Fig. $1 A$ ). While no bands were detectable in the TBS-soluble fraction from control brains, a $4 \mathrm{kDa}$ band, corresponding (under these denaturing conditions) to monomeric $\mathrm{A} \beta$, was observed in the TBS-soluble fraction from both $A P O E \varepsilon 3 / \varepsilon 3 \mathrm{AD}$ patient brains and $A P O E$ $\varepsilon 4 / \varepsilon 4 \mathrm{AD}$ patient brains. We also detected an $8 \mathrm{kDa}$ band corresponding to SDS-stable $\mathrm{A} \beta$ dimers, in the TBS-soluble fraction from several APOE $\varepsilon 4 / \varepsilon 4 \mathrm{AD}$ patient brains. To quantitate the concentration of $A \beta$, we applied synthetic $A \beta 1-42$ with known concentrations to the same gels and determined the concentration of $\mathrm{A} \beta$ in each TBS-soluble fraction. Despite the AD groups being matched for amyloid plaque burden (Fig. $1 C$ ), the level of TBS-soluble $\mathrm{A} \beta$ in $A P O E \varepsilon 4 / \varepsilon 4 \mathrm{AD}$ patient brains was 2.7 times higher than that in $A P O E \varepsilon 3 / \varepsilon 3 \mathrm{AD}$ patient brains, 6.9 times higher than that in $A P O E \varepsilon 2 / \varepsilon x \mathrm{AD}$ patient brains, and substantially times higher than the barely control brains' detectable levels $(2.7 \pm 5.0 \mu \mathrm{g} / \mathrm{g}$ brain lysate in control, $57.8 \pm 54.6 \mu \mathrm{g} / \mathrm{g}$ brain lysate in $A P O E \varepsilon 2 / \varepsilon X, 144.7 \pm 185.8 \mu \mathrm{g} / \mathrm{g}$ brain lysate in $A P O E$ $\varepsilon 3 / \varepsilon 3 \mathrm{AD}$ patient, and $396.9 \pm 315.0 \mu \mathrm{g} / \mathrm{g}$ brain lysate in $A P O E$ $\varepsilon 4 / \varepsilon 4 \mathrm{AD}$ patients; $p<0.05, \varepsilon 4 / \varepsilon 4$ vs $\varepsilon 3 / \varepsilon 3 ; p<0.01, \varepsilon 4 / \varepsilon 4$ vs $\varepsilon 2 / \varepsilon x$, control, $\varepsilon 3 / \varepsilon 3$ vs control; Fig. $1 B)$. We compared the amount of total soluble $\mathrm{A} \beta$ with the histochemically defined amounts of amyloid deposited in senile plaques, and found no correlation between plaque burden and levels of soluble $\mathrm{A} \beta$ (Fig. 
A

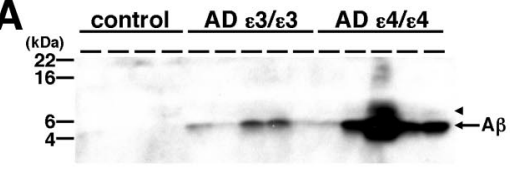

B

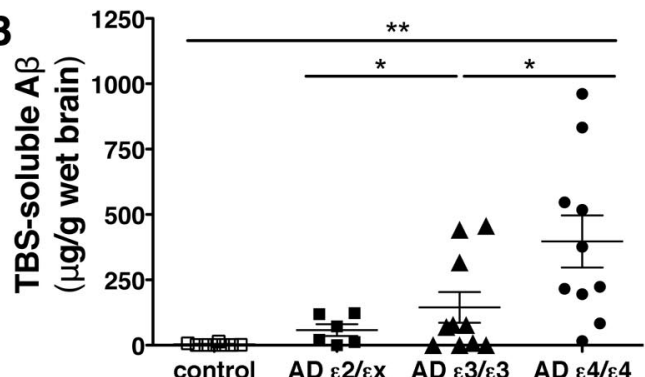

C

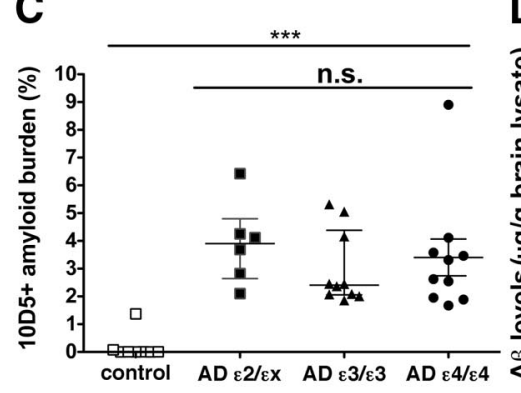

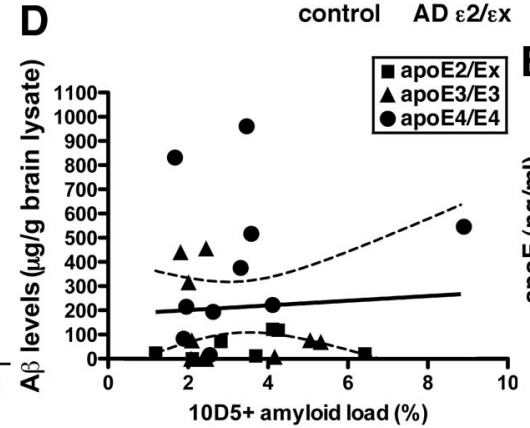

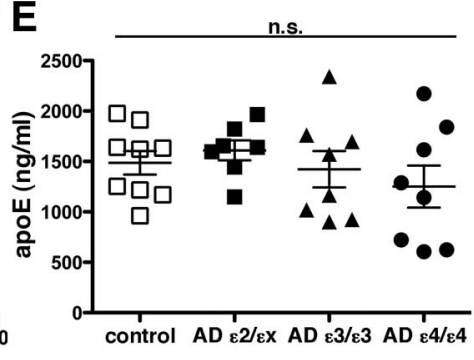

$\begin{array}{lllllllllll}(\mathrm{kDa}) & 217 & 143 & 94 & 56 & 30 & 16 & 11.7 & 8.6 & 4.6 & 3.0\end{array}$

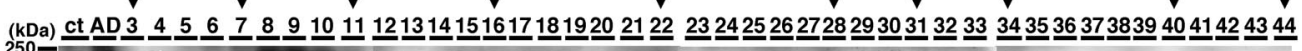
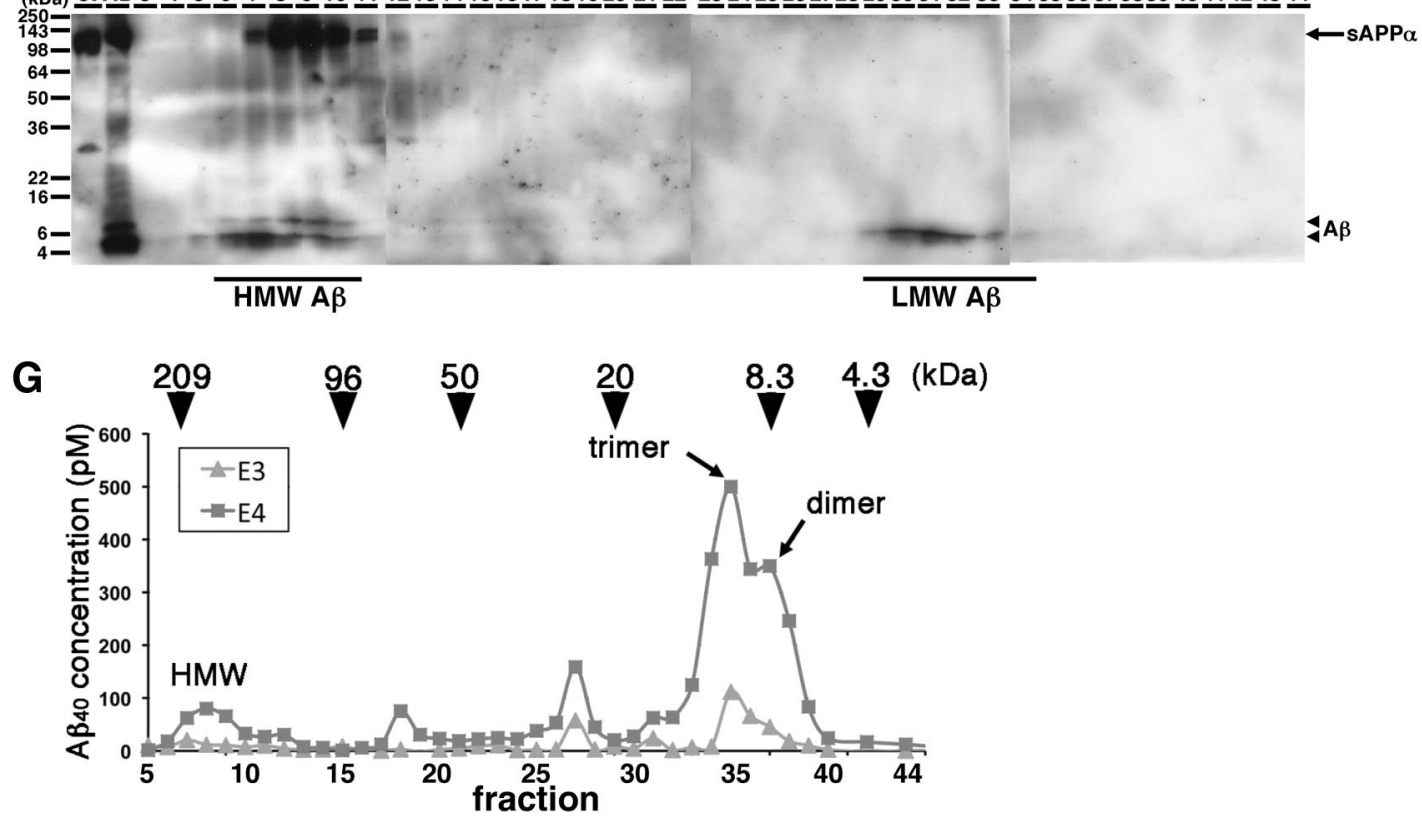

Figure 1. The level of $A \beta$ oligomers in the brain of $A P O E \varepsilon 4 / \varepsilon 4 A D$ patients was significantly higher compared with $A P O E \varepsilon 3 / \varepsilon 3 A D$ patients. $A$, Immunoblotting of $50 \mu$ of $T B S$-soluble fractions from 4 control, $5 A P O E \varepsilon 3 / \varepsilon 3 A D$, and 5 APOE $\varepsilon 4 / \varepsilon 4$ AD prefrontal brains. An anti-A $\beta$ mAb $82 E 1$ revealed $A \beta$ monomers (arrow) and dimers (arrowhead). $B$, Quantification of TBS-soluble $A \beta$ from 8 control (white squares), $6 A P O E \varepsilon 2 / \varepsilon \times A D$ (dark squares), $10 A P O E \varepsilon 3 / \varepsilon 3 A D$ (dark triangles), and $10 A P O E \varepsilon 4 / \varepsilon 4 A D$ brains (black circles). The level of $A \beta$ in $A P O E \varepsilon 4 / \varepsilon 4 A D$ brains was significantly higher compared with control brains, APOE $\varepsilon 2 / \varepsilon x A D$ brains, and APOE $\varepsilon 3 / \varepsilon 3$ AD brains. ${ }^{*} p<0.05,{ }^{* *} p<0.01$, one-way ANOVA test (Tukey's post hoc test). C, Amyloid burden (\%) in the prefrontal cortex of 8 control (white squares), $6 A P O E \varepsilon 2 / \varepsilon \times A D$ (dark squares), $10 A P O E \varepsilon 3 / \varepsilon 3 \mathrm{AD}$ (dark triangles), and $10 A P O E \varepsilon 4 / \varepsilon 4 \mathrm{AD}$ brains (black circles) analyzed in this study. There is no significant difference among $A P O E \varepsilon 2 / \varepsilon \times A D$, between $A P O E \varepsilon 3 / \varepsilon 3$ AD and APOE $\varepsilon 4 / \varepsilon 4$ AD brains, one-way ANOVA test (Kruskal-Wallis test). D, Correlation analysis between the level TBS-soluble A $\beta$ and the level of $A \beta$ amyloid burden in $6 A P O E \varepsilon 2 / \varepsilon \times A D$ (dark squares), $10 A P O E \varepsilon 3 / \varepsilon 3$ AD (dark triangles), and $10 A P O E \varepsilon 4 / \varepsilon 4$ AD brains (black circles). There is no significant difference. $\boldsymbol{E}$, Quantification of apoE concentration in the TBS-soluble fraction of 8 control (white squares), $6 A P O E \varepsilon 2 / \varepsilon x A D$ (dark squares), $10 A P O E \varepsilon 3 / \varepsilon 3 A D$ (dark triangles), and $10 A P O E \varepsilon 4 / \varepsilon 4 A D$ brains (black circles). $F$, Immunoblotting of SEC-separated fractions from APOE $\varepsilon 4 / \varepsilon 4$ AD brain. Anti-A $\beta$ mAb $82 E 1$ and 6 E10 revealed A $\beta$ (arrow) and sAPP $\alpha$ (arrowhead). A $\beta$ eluted from $94 \mathrm{kDa}$ to $217 \mathrm{kDa}$ as HMW A $\beta$ and eluted from 8.6 to $16 \mathrm{kDa}$ as LMW A $\beta$. Estimated molecular weight (kDa) was indicated above (arrowheads). $G$, Representative data of the separation of $200 \mathrm{mg}$ of TBS-soluble fractions of $A P O E \varepsilon 3 / \varepsilon 3$ AD (triangles) and APOE $\varepsilon 4 / \varepsilon 4$ AD (squares) brains by double Superdex 75 SEC columns. The concentration of A $\beta 40$ is measured by A $\beta$ specific ELISA (BNT77-BA27) (Wako). Estimated molecular weight ( $\mathrm{KDa}$ ) was indicated above (arrowheads). $\mathrm{A} \beta$ in TBS-soluble fraction formed dimer, trimer and HMW oligomers.

$1 D, r=-0.01, p=0.95)$. This suggests that the amount of TBS-soluble $\mathrm{A} \beta$ is independent of the amount of deposited amyloid plaques.

It has also been reported that the level of apoE protein in the brains of $A P O E \varepsilon 4 / \varepsilon 4$ carriers is smaller than that of $A P O E \varepsilon 3 / \varepsilon 3$
$\mathrm{AD}$ carriers or of $A P O E \varepsilon 2 / \varepsilon 2$ carriers (Riddell et al., 2008). We measured the concentration of apoE in TBS-soluble fraction from the brains of control and AD cases by specific ELISA and found that it is similar among control and AD cases regardless of genotypes (Fig. 1E). 

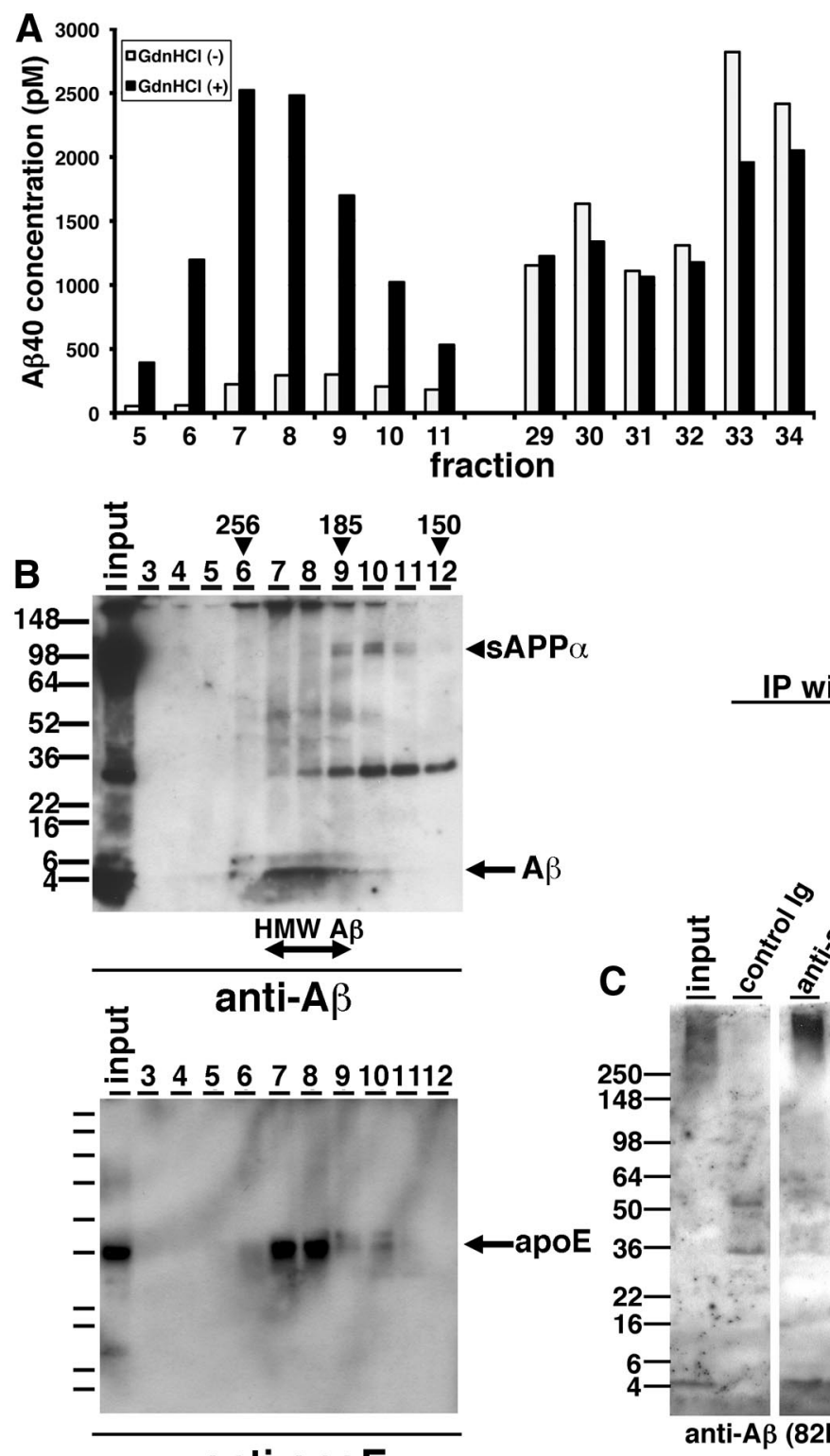

anti-apoE

Figure 2. apoEforms HMW complex with $\mathrm{A} \beta$ oligomers in the brains of AD patients. $A$, Representative data from guanidine- $\mathrm{HCl}$ treatment for SEC-separated fractions. SEC-separated fractions from 5 to 11 , from 29 to 34 were incubated with (black) or without (white) $8 \mathrm{~m}$ guanidine $\mathrm{HCl}$ and quantified the A $\beta$ concentration by specific ELISA (BNT77-BA27). B, Immunoblotting of SECseparated fractions (fraction 3-12) from an $A P O E \varepsilon 4 / \varepsilon 4$ AD brain. Top, Anti-mAbs $82 E 1$ and $6 E 10$ revealed $A \beta$ monomers (arrow), dimers, and sAPP $\alpha$ (arrowhead). Bottom, Anti-mAb $3 \mathrm{H} 1$ revealed apoE (arrow). Estimated molecular weight (kDa) is indicated above (arrowheads). C, Immunoprecipitation using anti-apoE antibodies and control antibody from SEC-separated fraction 8 and immunoblotted by an anti-A $\beta$ mAb 82E1. A $\beta$ monomers and dimmers were detected (arrows).

The finding of SDS-stable $\mathrm{A} \beta$ dimers in the TBS-soluble fraction of some $A P O E \varepsilon 4 / \varepsilon 4 \mathrm{AD}$ patients brains (Fig. $1 A$ ) prompted us to further characterize the presence of TBS-soluble $A \beta$ oligomers under native conditions. We separated TBS-soluble fractions by SEC. We applied the TBS-soluble fraction of APOE $\varepsilon 4 / \varepsilon 4$ AD patient brain onto two (tandem) Superdex 75 SEC columns (Townsend et al., 2006), collected fractions, applied the fractions into SDS-polyacrylamide gels, and detected $\mathrm{A} \beta$ by the antihuman $\mathrm{A} \beta$ antibody $6 \mathrm{E} 10$ (Fig. $1 F$ ). We found that fractions eluting from $94 \mathrm{kDa}$ to $217 \mathrm{kDa}$ strongly exhibited $4 \mathrm{kDa} \mathrm{A} \beta$ [hereafter called high-molecular weight (HMW) A $\beta$ ] and fractions eluting from $8.6 \mathrm{kDa}$ to $16 \mathrm{kDa}$ also exhibited $4 \mathrm{kDa} \mathrm{A} \beta$ [hereafter called low-molecular weight (LMW) A $\beta$ ]. To confirm these results and further refine this characterization, we applied the TBS-soluble fractions from 3 APOE $\varepsilon 3 / \varepsilon 3$ and 6 APOE $\varepsilon 4 / \varepsilon 4 \mathrm{AD}$ patients' brains onto two (tandem) Superdex 75 SEC columns, collected the eluted fractions, and measured the concentration of $\mathrm{A} \beta$ by an $\mathrm{A} \beta$-specific ELISA (Fig. 1G). Similar to the result of immunoblotting above (Fig. 1E), we found that $\mathrm{A} \beta$ eluted into fractions from 100 to $200 \mathrm{kDa}$ as $\mathrm{HMW} \mathrm{A} \beta$, fractions around $90 \mathrm{kDa}$, fractions around $30 \mathrm{kDa}$, and fractions from 6 to $20 \mathrm{kDa}$ (the latter LMW A $\beta$, likely reflecting $\mathrm{A} \beta$ dimers and $\mathrm{A} \beta$ trimers). Remarkably, we found that the TBS-soluble fraction from $A P O E$ $\varepsilon 4 / \varepsilon 4 \mathrm{AD}$ patient brains exhibited substantially higher amounts of $\mathrm{A} \beta$ in every peak compared with APOE $\varepsilon 3 / \varepsilon 3 \mathrm{AD}$ patient brains. Together, the level of TBSsoluble $\mathrm{A} \beta$ oligomers in APOE $\varepsilon 4 / \varepsilon 4 \mathrm{AD}$ patient brains was significantly higher than that in $A P O E \varepsilon 3 / \varepsilon 3 \mathrm{AD}$ patient brains.

ApoE forms HMW complex with A $\beta$ oligomers in the brains of AD patients Compared with immunoblotting results (Fig. $1 F$ ), we did not detect a strong signal of $\mathrm{A} \beta$ in HMW $\mathrm{A} \beta$ fractions by ELISA (Fig. $1 G$ ). We postulated that the structure of highly oligomeric $\mathrm{A} \beta$ may inhibit the interaction between $\mathrm{A} \beta$ and anti-A $\beta$ antibodies, or unidentified interacting molecules with $A \beta$ in the HMW fraction may interfere with the detection of $A \beta$ by anti-A $\beta$ antibodies used in the ELISA. To examine these possibilities, we incubated individual SEC fractions with or without 8 $\mathrm{M}$ guanidine- $\mathrm{HCl}$ for $30 \mathrm{~min}$ and quantified $\mathrm{A} \beta$ concentration by ELISA. We found that the measured concentration of $\mathrm{A} \beta$ in HMW fractions dramatically increased, while the levels of $\mathrm{A} \beta$ in LMW fractions exhibited no difference (Fig. $2 A)$, consistent with the idea that epitopes were masked in the HMW fraction.

ApoE is secreted in high-density lipoprotein (HDL) particles in the brain. To know whether apoE interacts with TBSsoluble $\mathrm{A} \beta$ oligomers and contributes to their apparent HMW, we immunoprobed $A \beta$ and apoE protein in each SEC-separated fraction of TBS-soluble fraction from APOE $\varepsilon 4 / \varepsilon 4 \mathrm{AD}$ patient brain using anti-A $\beta$ and anti-apoE antibodies on SDSpolyacrylamide gels (Fig. $2 B$ ). We found that $A \beta$ and apoE eluted in identical fractions, ranging from 185 to $256 \mathrm{kDa}$, suggesting that HMW A $\beta$ may interact with apoE on the HDL particles. We also detected HMW A $\beta$ and apoE in similar fractions from 185 to $256 \mathrm{kDa}$ using SEC-separated samples from the TBS-soluble fraction of an $A P O E \varepsilon 3 / \varepsilon 3 \mathrm{AD}$ patient brain. Immunoprecipitation of apoE using each of two separate polyclonal antibodies (antiapoE Ig, Calbiochem; and anti-apoE Ig, Millipore) pulled down $\mathrm{A} \beta$ from these fractions (Fig. $2 C$ ). These data suggest that apoE 
interacts with $\mathrm{A} \beta$ oligomers in human $\mathrm{AD}$ brain and thus may impact their oligomerization in the brain.

Purified apoE on HDL particles enhances synthetic $A \beta 1-42$ oligomer formation in vitro

We hypothesized that apoE on HDL particles would affect the $A \beta$ oligomerization in the brain in an isoform-dependent manner. In an in vitro $\mathrm{A} \beta$ fibrillization assay, apoE is known to inhibit $\mathrm{A} \beta$ fibrillization especially in the seeding phase of $A \beta$ fibrillization (Evans et al., 1995; Naiki et al., 1997). Because these experiments used recombinant nonlipidated apoE and because they evaluated the level of $\mathrm{A} \beta$ fibrillization using the thioflavin $T$ dye, which specifically interacts with $\beta$-sheeted structures but not oligomers, we reevaluated this interaction using physiologically relevant lipids and synthetic $A \beta$. We purified apoE lipid particles from immortalized astrocyte cell lines derived from human apoE2, apoE3, or apoE4 knock-in mice. These immortalized astrocyte cells are known to secrete human apoEs in HDL-like particles into conditioned media (Morikawa et al., 2005). We incubated $0.1 \mathrm{mg} / \mathrm{ml}(\sim 22 \mu \mathrm{M})$ synthetic $\mathrm{A} \beta 1-42$ with or without $10 \mu \mathrm{g}$ of purified lipidated apoE2, apoE3, or apoE4 at $4^{\circ} \mathrm{C}$ for $0,1.5,6,12$, or $24 \mathrm{~h}$ in vitro and applied the samples to SDSpolyacrylamide gels (Fig. $3 A$ ). In the absence of apoE, the $\mathrm{A} \beta$ trimers and $\mathrm{A} \beta$ tetramers disappeared within $6 \mathrm{~h}$ and were replaced by smear bands after $6 \mathrm{~h}$ (Fig. 3A, PBS panel). In contrast, in the presence of lipidated apoE2, apoE3, or apoE 4 , the bands for $\mathrm{A} \beta$ trimers and $\mathrm{A} \beta$ tetramers gradually accumulated during the incubation period (Fig. 3A, apoE2, apoE3, apoE4 panels). Of note, qualitative inspection of the gels show that incubation of $A \beta$ with apoE3 or apoE4 yielded higher levels of $A \beta$ trimers and $A \beta$ tetramers than incubation with apoE2. This result may suggest that lipidated apoE enhanced the oligomerization of $\mathrm{A} \beta$ or stabilized the $\mathrm{A} \beta$ oligomers. To elucidate whether lipidated apoE stabilize $A \beta$ oligomers, we incubated synthetic $A \beta 1-42$ oligomers with $5 \mu \mathrm{g} / \mathrm{ml}$ lipidated apoE2, apoE3, or apoE4 for $12 \mathrm{~h}$ in vitro, applied the samples to SDS-polyacrylamide gels, and quantified the level of remaining $\mathrm{A} \beta$ oligomers (Fig. $3 B$ ). Lipidated apoE 4 significantly increased the level of $A \beta$ trimers and tetramers compared with the sample incubated without apoE $(130.0 \pm 19.0 \%$ in trimers and $235.3 \pm 85.4 \%$ in tetramers), suggesting that apoE 4 may stabilize the $\mathrm{A} \beta$ oligomers. On the other hand, lipidated apoE2 and apoE3 did not exhibit significant increase of the level of the $\mathrm{A} \beta$ oligomers (Fig. $3 B$ ).

Because the concentration of $A \beta$ oligomers is quite small, it is difficult to quantitatively monitor $A \beta$ oligomers using these techniques. To evaluate the role of apoE in the formation of $\mathrm{A} \beta$ oligomers, we took advantage of a recently developed method using a split-luciferase complementation assay (Hashimoto et al., 2011). In this assay, the $\mathrm{N}$ - and C-terminal fragments of Gaussia luciferase are fused separately to $A \beta$, so that single split-luciferase-tagged $A \beta$ does not exhibit
Incubation (hrs)
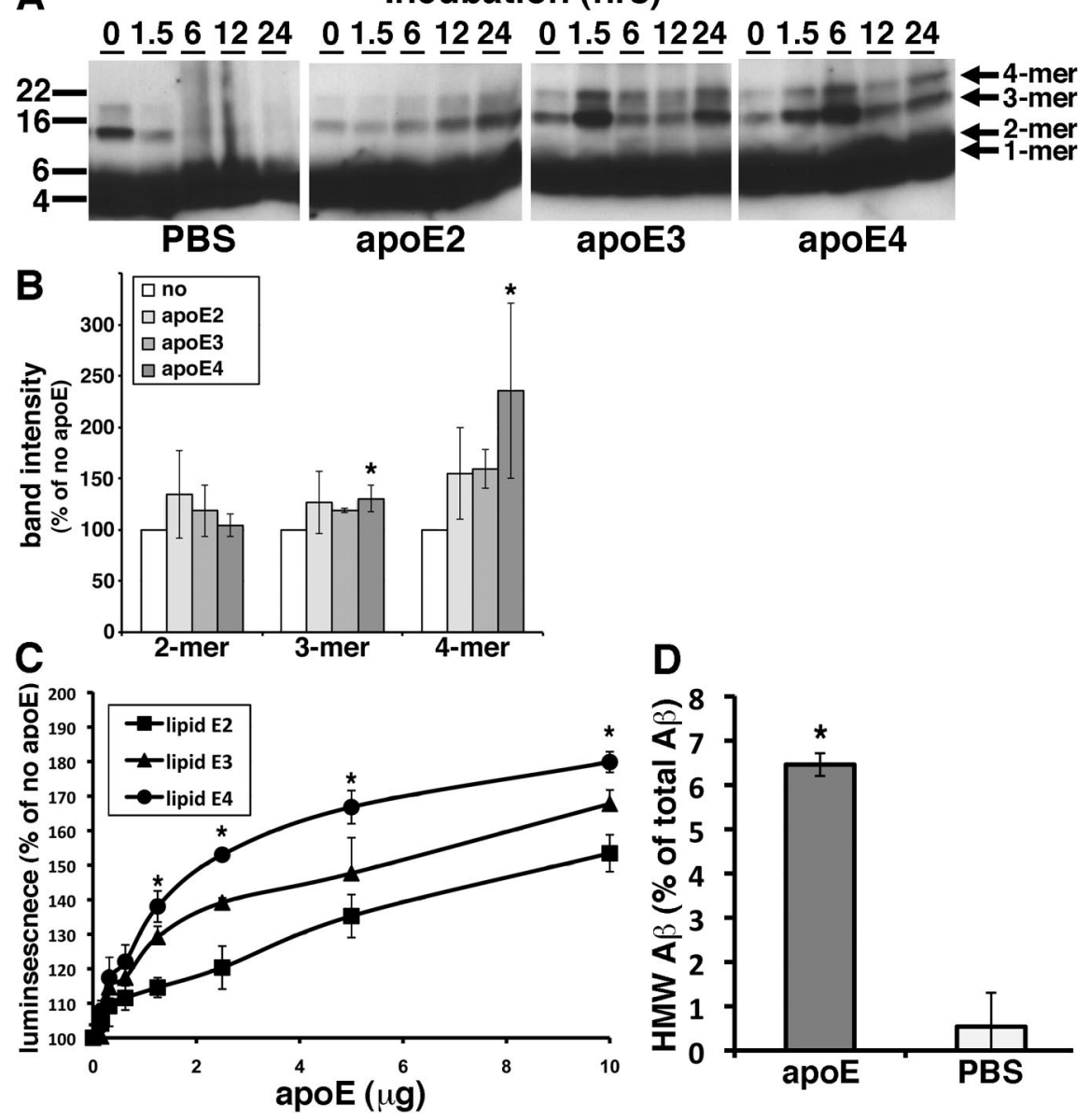

Figure 3. Purified apoE-containing HDL particles enhanced oligomer formation of synthetic $A \beta 1-42$ in vitro. $\boldsymbol{A}$, ImmunoblotapoE2, apoE3, or apoE4 for $12 \mathrm{~h}$ using an anti-A $\beta$ mAb 6E10. Lipidated apoE4 significantly increased the level of $A \beta$ roni's test). $C$, Luminescence from conditioned media containing split-luciferase-tagged $A \beta$ oligomers incubated with $0,0.1,0.3$, apoE4, circles) for 24 h. $N=6$, average $\pm S D,{ }^{*} p<0.05$, one-way ANOVA test (Bonferroni's test). $\boldsymbol{D}$, Incubation of LMW A $\beta$ isolated from TBS-soluble fractions of the AD brains with (apoE) or without (PBS) $5 \mu \mathrm{g}$ of purified lipid apoE3 and separated the samples by double Superdex 75 SEC columns. The concentration of A $\beta 40$ was measured by A $\beta$-specific ELISA (BNT77-BA27, WAKO Chemicals) and obtained the ratio of HMW A $\beta$ measured (in fraction 7 and 8 ). $N=4$, average $\pm S D,{ }^{*} p<0.05$, student' $t$ test.

luminescence. Once split-luciferase-tagged $\mathrm{A} \beta$ forms oligomers, the $\mathrm{N}$ - and C-terminal fragments of luciferase reconstitute into a functional molecule that exhibits luminescence (Hashimoto et al., 2011). This technique has the advantage of monitoring $\mathrm{A} \beta$ oligomers specifically and quantitatively without background from monomers. We incubated split-luciferase-tagged $\mathrm{A} \beta$ oligomers with $0,0.1,0.3$, $0.6,1.25,2.5,5$, and $10 \mu \mathrm{g}$ of purified lipidated apoE2, apoE3, or apoE4 for $24 \mathrm{~h}$ and measured the luminescence (Fig. $3 C$ ). We found that purified lipidated apoE in a dose-dependent manner enhanced the level of $\mathrm{A} \beta$ oligomers in an isoform-dependent manner (apoE2 $<$ apoE3 $<$ apoE4). Moreover, we isolated LMW A $\beta$ from TBS-soluble fraction of the brains of APOE $\varepsilon 4 / \varepsilon 4 \mathrm{AD}$ patients by SEC, incubated with or without $5 \mu \mathrm{g}$ of purified lipidated apoE3, applied to two (tandem) Superdex 75 SEC columns again, and quantified the level of $\mathrm{A} \beta$ by the specific ELISA. We found that after incubation with purified lipidated apoE, $\sim 6.5 \%$ of LMW A $\beta$ instead elutes in the HMW A $\beta$ fraction (Fig. $3 D, 6.5 \pm 0.3 \%$ with apoE, 
$0.5 \pm 0.7$ without apoE), an increase of over tenfold. These qualitative and quantitative data suggest that lipidated apoE enhances $\mathrm{A} \beta$ oligomerization and inhibited further aggregation in vitro.

apoE enhances the level of $\mathrm{A} \boldsymbol{\beta}$ oligomers in an isoformdependent manner (apoE $2<$ apoE3 < apoE4)

Using the split-luciferase complementation assay for monitoring $\mathrm{A} \beta$ oligomers, we further examined apoE's effect on $\mathrm{A} \beta$ oligomers. First we transiently transfected apoA-II, apoE2, apoE3, and apoE4 into doubly expressing HEK293 cells stably expressing both $\mathrm{N}$ - and C-terminal fragments of luciferasetagged $A \beta$, collected their conditioned media after $24 \mathrm{~h}$ of incubation, and measured $\mathrm{A} \beta$ oligomers by measuring luminescence in the media (Fig. $4 A, B$ ). We found that apoE2, apoE3, or apoE4 each increased the luminescence. On the other hand, apoA-II, one of the other apolipoproteins in brain HDL particles, did not change the luminescence compared with GFP transfection $(91.8 \pm 5.1 \%$ in apoA-II, $200.3 \pm$ $10.2 \%$ in apoE2, $275.5 \pm 15.0 \%$ in apoE3, $338.1 \pm 18.5 \%$ in apoE4; $p<0.05$, E2 vs E3; E3 vs E4). apoA-II was therefore used as a control transfection for subsequent experiments.

apoE4 significantly increased the luminescence to a greater extent than apoE2 and apoE3, and apoE3 significantly increased the luminescence to a greater extent than apoE2, suggesting that apoE enhanced the level of $\mathrm{A} \beta$ oligomers in an isoform-dependent manner (apoE2 $<$ apoE3 $<$ apoE4). We did not see any difference in the levels of apoE in the conditioned media (Fig. $4 B$ ).

Although HEK293 cells transfected with human apoE3 and apoE4 naturally secrete apoE lipoparticles into the culture media ( $\mathrm{LaDu}$ et al., 2006), we asked whether the induction of $\mathrm{A} \beta$ oligomerization by apoE might actually be taking place within the cells, before the secretion of apoE to the conditioned media. To test this, we transfected apoA-II, apoE2, apoE3, and apoE4 into doubly expressing HEK293 cells, collected cell lysates after $24 \mathrm{~h}$ incubation and measured the luminescence in cell lysates (Fig. $4 C$ ). We found that apoE2, apoE3, and apoE4 did not enhance the luminescence within cell lysates $(100.0 \pm 12.7 \%$ in apoA-II, $89.9 \pm 9.7 \%$ in apoE2, $96.4 \pm 13.9 \%$ in apoE3, $92.5 \pm 2.2 \%$ in apoE4, no significant difference). Nevertheless they strongly increased the luminescence in the conditioned media (Fig. 4A), suggesting that apoE influences $\mathrm{A} \beta$ oligomers only in the extracellular compartment.

These data suggest that lipidated apoE2, 3, or 4 supports oligomeric $\mathrm{A} \beta$ generation to different extents, and we hypothesized that this was due to differences in their conformation (Jones et al., 2011). apoE2 and apoE3 prefer an open conformation, whereas apoE4 prefers a closed conformation due to a difference at amino acid residue 112 between apoE4 (Arg) and apoE2, E3 (Cys) (Dong et al., 1994; Mahley et al., 2009); indirectly this changes a salt bridge and alters the domain-domain interactions of the amino and carboxyl halves of apoE. To test the hypothesis that the difference of the tertiary structure of apoE is responsible for the observed isoform-dependent differences in apoE's facilitation of oligomer formation, we examined the effects of the apoE4 R61T mutation, which is known to change the apoE4 conformation so that it mimics the closed apoE3 conformation (Ye et al., 2005). We transiently transfected apoA-II, apoE3, apoE4, or apoE4 R61T into doubly expressing HEK293 cells, collected conditioned media after $24 \mathrm{~h}$ incubation, and measured its luminescence in the media (Fig. 4D). We found that apoE4 R61T increased the level of $A \beta$ oligomers to the same extent as apoE3, but not as high as apoE4, suggesting that the tertiary structure of

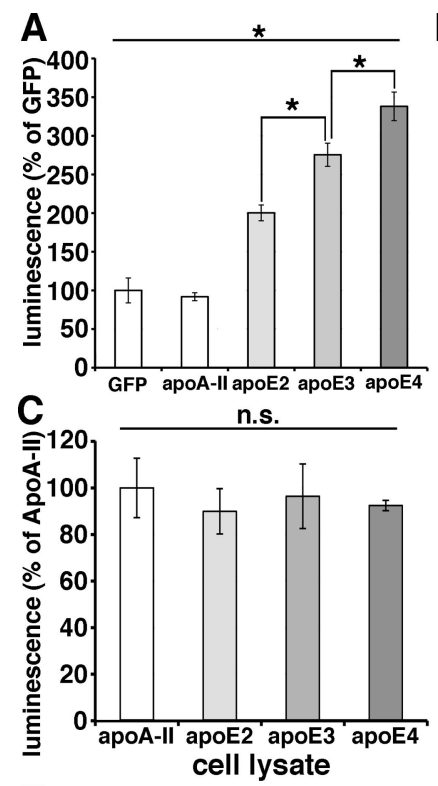

B
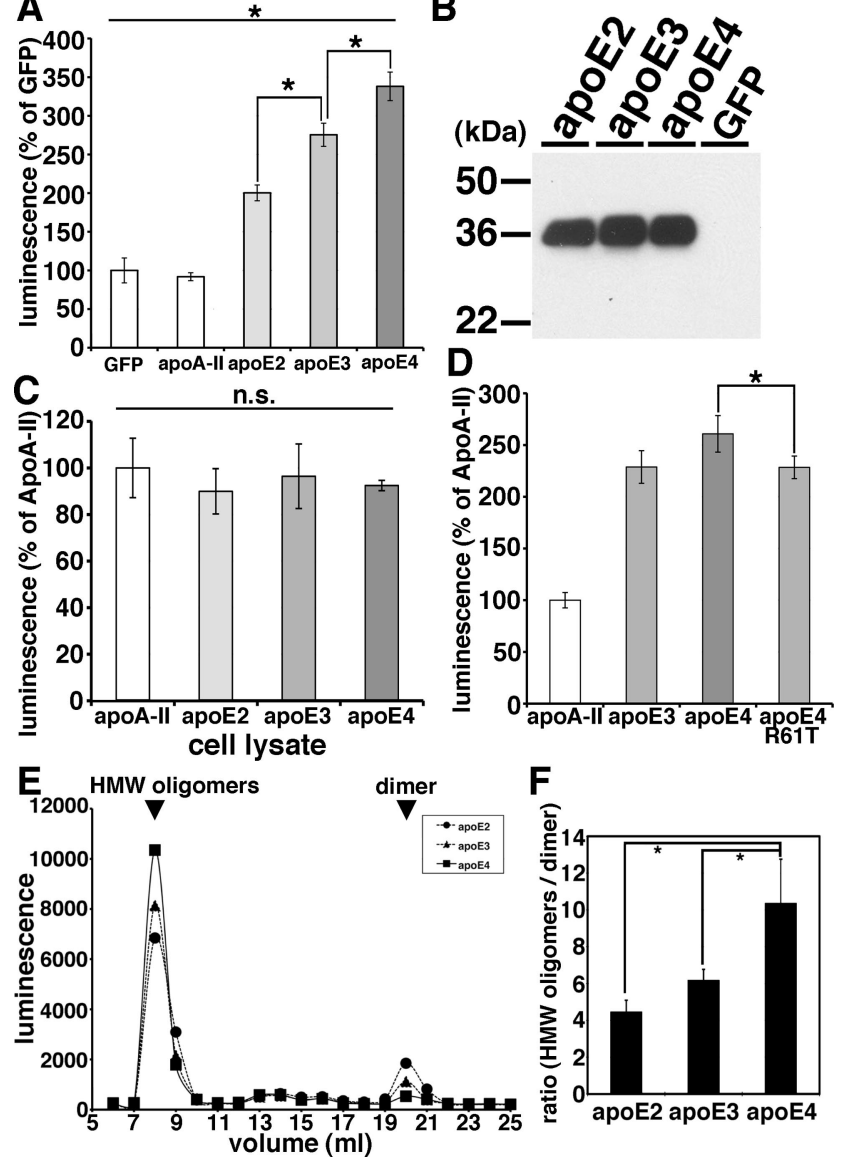

Figure 4. ApoE enhanced the level of $A \beta$ oligomers in an isoform-dependent manner. $\boldsymbol{A}$, Transient transfection of GFP (control), apoA-II, apoE2, apoE3, or apoE4 into double-expressing HEK293 cells. Luminescence of conditioned media was measured. apoE3 significantly increased the luminescence compared with apoE2 and apoE4 significantly increased the luminescence compared with apoE3. $N=6$, average $\pm S D,{ }^{*} p<0.05$, one-way ANOVA test (Bonferroni's test). $\boldsymbol{B}$, Immunoblotting of conditioned media from GFP (control), apoE2, apoE3, or apoE4 transiently transfected double-expressing HEK293 cells by an anti-apoE mAb 3H1. C, Transient transfection of apoA-II, apoE2, apoE3, or apoE4 into double-expressing HEK293 cells. Luminescence of cell lysates was measured. There is no significant difference of the luminescence among apoE2-, apoE3-, or apoE4-expressing cells. $N=6$, average \pm SD, one-way ANOVA test (Bonferroni's test). $\boldsymbol{D}$, Transient transfection of apoA-II, apoE3, apoE4, or apoE4 R61T mutant into double-expressing HEK293 cells. Luminescence of conditioned media was measured. apoE4 significantly increased the luminescence compared with apoE4 R61T mutant. $N=6$, average $\pm S D,{ }^{*} p<0.05$, one-way ANOVA test (Bonferroni's test). $\boldsymbol{E}$, Transient transfection of apoE2, apoE3, or apoE4 into double-expressing HEK293 cells and separation of conditioned media by a SEC column Superdex 200. Representative data of the luminescence profile of the elutants from conditioned media of apoE2 (circles)-, apoE3 (triangles)-, or apoE4 (squares)transfected cells. Two peaks, HMW oligomers and dimers (arrows) were observed. F, Average ratio between $\mathrm{HMW}$ oligomers and dimers. $N=3$, average $\pm S D,{ }^{*} p<0.01$, one-way ANOVA test (Bonferroni's test).

apoE is relevant to the apoE isoform-dependent effect on $\mathrm{A} \beta$ oligomerization ( $100.80 \pm 7.4 \%$ in apoA-II, $228.8 \pm 15.8 \%$ with apoE3, $260.8 \pm 17.7 \%$ with apoE4, $228.4 \pm 10.9 \%$ with apoE4 R61T; $p<0.05$, E4 vs E4 R61T). We did not see any difference in the levels of apoE expression among apoE3, apoE4, and ApoE4 R61T.

We previously demonstrated that the split-luciferase-tagged A $\beta$ oligomers consist of HMW 24 36 mer and low-molecular weight dimers by SEC analyses (Hashimoto et al., 2011). To evaluate whether apoE shifts the molecular size of $\mathrm{A} \beta$ oligomers, we separated conditioned media from apoE2, apoE3, or apoE4 transiently transfected doubly expressing HEK293 cells using a single 
Superdex 200 SEC column, collected the eluted fractions, and measured their luminescence (Fig. $4 E$ ). We found that apoE4 significantly increased the level of HMW putative $24 \sim 36$ mer oligomers (or complexes of $\mathrm{A} \beta$ with other proteins) and decreased the level of dimers (Fig. $4 E, F, p<0.01$ ). We observed no significant shift in the elution profile of $\mathrm{A} \beta$ oligomers by apoEs.

apoA-I and apo J/clusterin also enhanced $\mathrm{A} \boldsymbol{\beta}$ oligomerization In addition to apoE, apoA-I, apoA-II, and apoJ/clusterin are also present on the HDL particles in the brain. Recently, several genome-wide association studies have identified a variant at $C L U$ (gene of apoJ/clusterin) to be associated with Alzheimer's disease (Harold et al., 2009; Lambert et al., 2009). It has also been reported that apoJ/clusterin-deficient mice crossed with APPtransgenic mice exhibit significantly fewer fibrillar $\mathrm{A} \beta$ deposits in the brain compared with APP-transgenic mice (DeMattos et al., 2002). Hence we asked whether these other apolipoproteins might also modulate $\mathrm{A} \beta$ oligomerization. To address this question, we transiently transfected apoA-I, apoA-II, apoJ, and apoE3 into doubly expressing HEK293 cells, collected their conditioned media after $24 \mathrm{~h}$ incubation, and measured their luminescence (Fig. 5). Interestingly, apoA-I and apoJ/clusterin also enhanced the luminescence, although to a lesser extent than apoE3, whereas apoA-II did not change the luminescence from baseline (132.0 \pm $7.0 \%$ in apoA-I, $89.3 \pm 6.6 \%$ in apoA-II, $163.5 \pm 12.1 \%$ in apoJ/ clusterin, $278.8 \pm 26.0 \%$ in apoE3, $p<0.05)$. This suggests that apoA-I and apoJ/clusterin may also modulate the metabolism of $\mathrm{A} \beta$ oligomers in the brain, and reinforces the idea that lipidated particles supported by several apolipoproteins may act as a scaffold for $\mathrm{A} \beta$ interactions.

\section{The lipid-binding domain of apo $\mathrm{E}$ is necessary for enhancement of $\mathbf{A} \boldsymbol{\beta}$ oligomerization}

apoE has a receptor-binding domain in the $\mathrm{N}$-terminal region and a lipid-binding domain in the $\mathrm{C}$-terminal region (Fig. 6A; Chou et al., 2005). To understand which domain of apoE is important in the enhancement of $A \beta$ oligomerization, we expressed the apoE NTFs (apoE2 NTF, apoE3 NTF, apoE4 NTF) or apoE CTF in double-expressing HEK293 cells, collected conditioned media after $24 \mathrm{~h}$ incubation and measured their luminescence (Fig. $6 B, C$ ). We found that apoE2 NTF, apoE3 NTF, or apo4 NTF did not enhance the luminescence, whereas apoE CTF significantly enhanced the luminescence to an extent similar to that of full-length apoE3 $(80.4 \pm 13.4 \%$ for apoE2 NTF, $103.1 \pm 9.2 \%$ for apoE3 NTF, $104.5 \pm 8.6 \%$ for apoE4 NTF, compared with $175.5 \pm 22.6 \%$ for apoE CTF and $191.5 \pm 13.2 \%$ with full-length apoE3; $p<0.05$, apoE3 and apoE3 CTF; no significant difference, apoE2 NTF, apoE3 NTF, and apoE4 NTF). This suggests that the $\mathrm{C}$-terminal region of apoE is necessary and sufficient to induce $\mathrm{A} \beta$ oligomerization. We also coexpressed both apoE3 and apoE3 NTF together in doubly expressing HEK293 cells and found that apoE3 NTF did not inhibit the enhancing effect of apoE3, suggesting that the N-terminal fragments of apoE is a loss-offunction molecule regarding $A \beta$ oligomerization (Fig. $6 B$, $166.9 \pm 19.2 \%$ in apoE3 and apoE3 NTF, $p<0.05$ ). In immunoblotting, we confirmed the expression of these apoE fragments using anti-human apoE antibodies. Mab 6C5, its epitope located in the N-terminal region of apoE, recognized full-length apoE3, apoE2 NTF, apoE3 NTF, and apoE4 NTF (Fig. 6A,C). Mab 3H1 (epitope located at 243-272 aa residues of apoE), recognized fulllength apoE3 and apoE CTF (Fig. 6A,C).

The C-terminal domain of apoE contains the major lipidbinding region (243-272 aa residues; Hatters et al., 2006; Mahley et

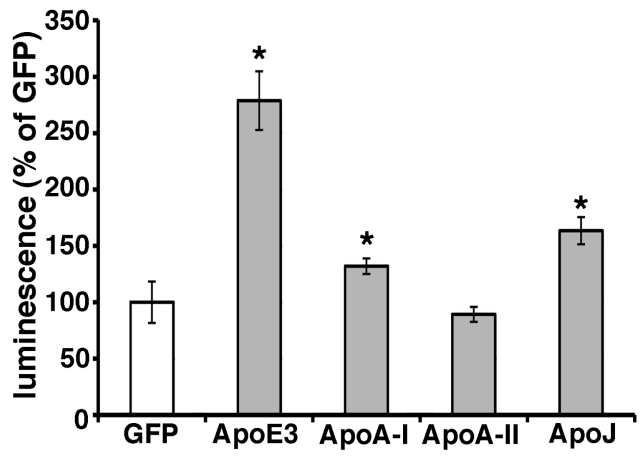

Figure 5. ApoA-I and apoJ enhanced the level of $A \beta$ oligomers. Transient transfection of GFP (control), apoA-I, apoA-II, apoJ/clusterin, or apoE3 into double-expressing HEK293 cells. Luminescence of conditioned media was measured. apoA-I, apoJ/clusterin, or apoE3 significantly increased the luminescence. $N=6$, average $\pm S D,{ }^{*} p<0.05$, one-way ANOVA test (Bonferroni's test).

al., 2009). To find the C-terminal domain of apoE responsible for the enhancement of $A \beta$ oligomerization, we next expressed apoE 231299, apoE 243-299, apoE192-272, and apoE 192-242 in A $\beta$ splitluciferase-expressing HEK293 cells, collected conditioned media after $24 \mathrm{~h}$ incubation, and measured the luminescence (Fig. $6 D$ ). We found that apoE 231-299 and apoE 243-299 increased the luminescence to the same level as apoE CTF, whereas apoE 192-272 did not increase the luminescence as strongly as apoE CTF. apoE 192-242 luminescence was even lower than that of apoE 192-272 (91.7 \pm $3.9 \%$ in apoA-II, $274.4 \pm 24.4 \%$ in apoE3, $112.9 \pm 13.1 \%$ in apoE3 NTF, $239.0 \pm 7.6 \%$ in apoE CTF, $222.9 \pm 6.0 \%$ in apoE 231-299, $235.3 \pm 14.5 \%$ in apoE $243-299,184.9 \pm 8.3 \%$ in apoE $192-272$, $142.0 \pm 4.0 \%$ in apoE $192-242 ; p<0.05$, apoA-II vs apoE3, apoE CTF, apoE 231-299, or apoE 243-299; apoE CTF vs apoE 192-272; apoE 192-272 vs apoE 192-242). Together, these data suggest that the 243-299 aa residues in the C-terminal region of apoE are especially important in the enhancement of $\mathrm{A} \beta$ oligomers. We confirmed similar expression levels of these apoE fragments by immunoblotting using a goat anti-apoE polyclonal antibody and $\mathrm{mAb} 3 \mathrm{H} 1$.

To further examine the effect of the 243-299 aa residues of apoE in the enhancement of the $\mathrm{A} \beta$ oligomerization, we also expressed the deletion mutants, apoE3 $\Delta 243-272$, apoE3 $\Delta 273-$ 299 , and apoE3 $\Delta 243-299$, collected culture media after $24 \mathrm{~h}$ incubation, and measured their luminescence (Fig. 6E). We found that apoE3 $\Delta 243-272$, apoE3 $\Delta 273-299$, and apoE3 $\Delta 243-$ 299 significantly decreased the level of luminescence compared with full-length apoE3 and that apoE3 $\Delta 243-299$ significantly decreased the luminescence compared with apoE3 $\Delta 273-299$ $(218.1 \pm 19.7 \%$ in apoE3, $114.0 \pm 7.1 \%$ in apoE3 NTF, $205.9 \pm$ $7.2 \%$ in apoE CTF, $154.4 \pm 6.8 \%$ in apoE3 $\Delta 243-272,176.8 \pm$ $13.5 \%$ in apoE3 $\Delta 273-299,143.8 \pm 10.0 \%$ in apoE3 $\Delta 243-299$; $p<0.01$, apoA-II vs apoE3 or apoE CTF; $p<0.05$, apoE3 vs apoE3 $\Delta 243-272$, apoE3 $\Delta 273-299$, or apoE3 $\Delta 243-299$; apoE3 $\Delta 273-299$ vs apoE3 $\Delta 243-272$ or apoE3 $\Delta 243-299)$. We confirmed similar expression levels of these apoE mutants by immunoblotting using $\mathrm{mAb} 6 \mathrm{C} 5$ and $\mathrm{mAb} 3 \mathrm{H} 1$. Together, these results strongly argue that the C-terminal region of apoE, especially a domain within amino-acid residues 243-272, is essential for apoE's support of $A \beta$ oligomers. This domain is the major lipidbinding domain of apoE; thus, the lipidation of apoE may be crucial in the enhancement of $A \beta$ oligomerization, as this region may act to help catalyze oligomer formation. 


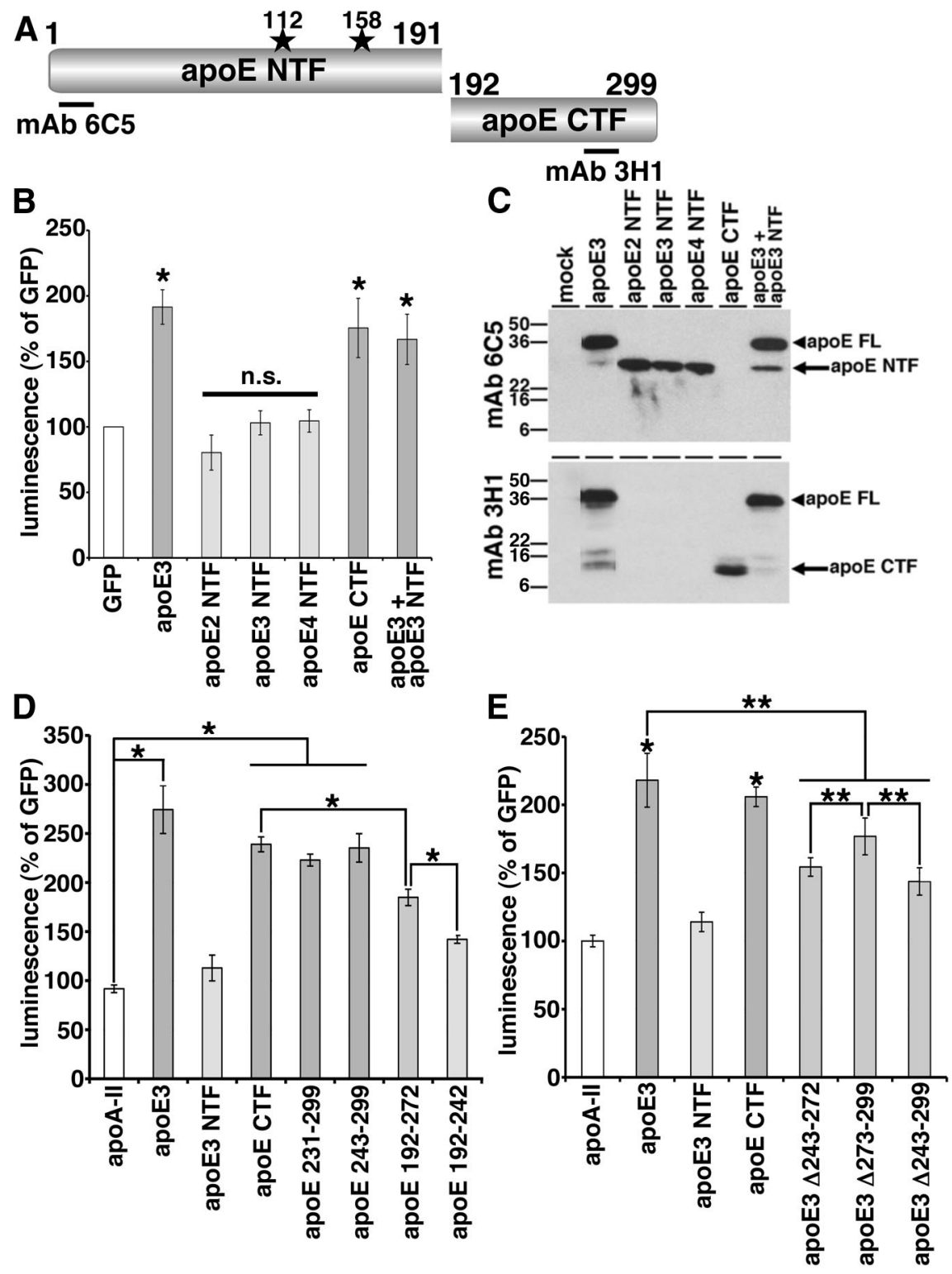

Figure 6. Lipid-binding domain of apoE was necessary for the enhancement of $A \beta$ oligomers. $\boldsymbol{A}$, Schematic structure of apoE and apoE fragments. The epitopes of $m A b 6 C 5$ and $m A b 3 H 1$ is illustrated. $B$, Transient transfection of GFP, apoE3, apoE2 NTF, apoE3 NTF, apoE4 NTF, apoE CTF, or both apoE3 and apoE3 NTF into double-expressing HEK293 cells. Luminescence of conditioned media was measured. apoE3 and apoE CTF significantly increased the luminescence, on the other hand, apoE2 NTF, apoE3 NTF, or apoE4 NTF did not increase the luminescence. $N=6$, average $\pm S D,{ }^{*} p<0.05$, one-way ANOVA test (Bonferroni's test). C, Immunoblotting of conditioned media by the anti-apoE mAb 6C5 (top) and 3H1 (bottom panel). MAb 6C5 revealed $36 \mathrm{kDa}$ band (full-length apoE, arrowhead) and $26 \mathrm{kDa}$ band (apoE NTF, arrow). MAb 3H1 revealed also $36 \mathrm{kDa}$ band (full-length apoE, arrowhead) and $10 \mathrm{kDa}$ doublet band (apoE (TF, arrow). D, Transient transfection of GFP, apoA-II, apoE3, apoE3 NTF, apoE CTF, apoE 231-299, apoE 243-299, apoE 192-272, and apoE 192-242 into double-expressing HEK293 cells. Luminescence of conditioned media was measured. apoE3 significantly increased the luminescence compared with apoA-II, apoE CTF fragments. apoE CTF significantly increased the luminescence compared with apoE 192-272 and apoE 192-272 significantly increased the luminescence compared with apoE 192-242. $N=6$, average $\pm S D,{ }^{*} p<0.05$, one-way ANOVA test (Bonferroni's test). $\boldsymbol{E}$, Transient transfection of GFP, apoA-II, apoE3, apoE3 NTF, apoE CTF, apoE3 $\Delta 243-272$, apoE3 $\Delta 273-299$, and apoE3 $\Delta 243-299$ into double-expressing HEK293 cells. Luminescence of conditioned media was measured. apoE3 and apoE CTF significantly increased the luminescence compared with apoA-II. ApoE3 also significantly increased the luminescence compared with three apoE3 deletion mutants. ApoE3 $\Delta 273-299$ significantly increased the luminescence compared with apoE3 $\Delta 243-272$ or apoE3 $\Delta 243-299 . N=6$, average $\pm \mathrm{SD},{ }^{*} p<0.01,{ }^{* *} p<0.05$, one-way ANOVA test (Bonferroni's test).

Human brain apoE promoted $\mathrm{A} \boldsymbol{\beta}$ oligomerization

Since lipidated apoE particles generated in culture enhanced $\mathrm{A} \beta$ oligomerization, we next tested whether apoE isolated from human brain might have the same effect. We separated the TBS- extract of human brain by SEC and found both apoE and HMW $A \beta$ oligomers are eluted into fraction 7 and 8 (Fig. $2 B$ ). We first incubated SEC-separated TBSsoluble fractions 6-9 from $\mathrm{AD} A P O E$ $\varepsilon 3 / \varepsilon 3$ brains, $\mathrm{AD} A P O E \varepsilon 4 / \varepsilon 4$ brains (Fig. $7 A$ ), or control brains (Fig. $7 B$ ) with conditioned media from doubly expressing HEK293 cells for $24 \mathrm{~h}$ at $37^{\circ} \mathrm{C}$, and measured the luminescence. We observed that all four fractions, but especially fraction 8 from both $\mathrm{AD}$ and control brains, increased the luminescence $(141.8 \%$ in $\mathrm{AD}$ fraction $6,198.4 \%$ in $\mathrm{AD}$ fraction 7 , $256.4 \%$ in $\mathrm{AD}$ fraction $8,207.6 \%$ in $\mathrm{AD}$ fraction $9,99.8 \%$ in control fraction 6 , $163.2 \%$ in control fraction $7,230.8 \%$ in control fraction $8,202.6 \%$ in control fraction 9). We also found that apoE eluted in fraction 8 from $\mathrm{AD}$ and control brain by immunoblotting using a goat anti-apoE antibody (Fig. $7 A, B$, bottom). Next, to test the hypothesis that apoE mediated the increase in luminescence observed due to fraction 8 , we immunodepleted apoE from fraction 8 using an anti-human apoE $\mathrm{mAb} 3 \mathrm{H} 1$, incubated with conditioned media from doubly expressing HEK293 cells for $24 \mathrm{~h}$ at $37^{\circ} \mathrm{C}$, and measured the luminescence (Fig. 7C). We found that apoE-immunodepleted sample significantly decreased the level of luminescence compared with immunodepletion using a control antibody $(261.8 \pm 47.3 \%$ with no antibody, $168.1 \pm 44.6 \%$ with anti-apoE antibody, $237.1 \pm 24.5 \%$ with control antibody, $p<0.05)$. Moreover, it is these fractions that were used for the immunoprecipitation of apoE and $\mathrm{A} \beta$ described above (Fig. 2C). Finally, we incubated fraction 8 from $4 \mathrm{AD}$ patients with the $A P O E \varepsilon 4 / \varepsilon 4$ genotype and $4 \mathrm{AD}$ patients with the APOE $\varepsilon 3 / \varepsilon 3$ genotype with conditioned media from doubly expressing HEK293 cells for $24 \mathrm{~h}$ at $37^{\circ} \mathrm{C}$, and measured the luminescence (Fig. 7D). We observed that fractions from $A P O E \varepsilon 4 / \varepsilon 4$ $\mathrm{AD}$ patients led to significantly increased levels of $\mathrm{A} \beta$ oligomers compared with that from $A P O E \varepsilon 3 / \varepsilon 3 \mathrm{AD}$ patients (193.0 \pm $4.9 \%$ in $A P O E$ \& $4 / \varepsilon 4 \mathrm{AD}$ patients and $167.6 \pm 6.8 \%$ in $A P O E \varepsilon 3 / \varepsilon 3 \mathrm{AD}$ patients, $p<0.05)$. These data indicate that endogenous apoE from human brain increased the level of $A \beta$ oligomers, supporting the hypothesis that lipidated apoE derived from human brain also enhances $A \beta$ oligomerization. The residual enhancement of luminescence after immunodepletion might be due to incomplete immunodepletion, the preservation of lipidated particles that do not contain apoE, or other non-apoE factors (including oligomeric $\mathrm{A} \beta$ itself) that might act as a nidus for oligomer formation. 
A
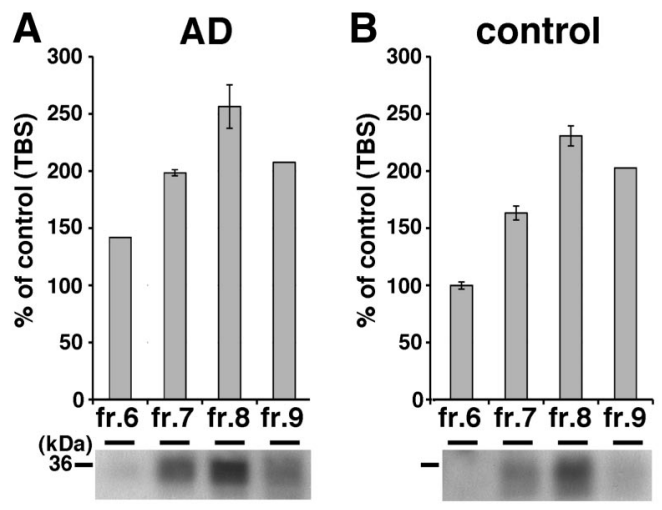

C

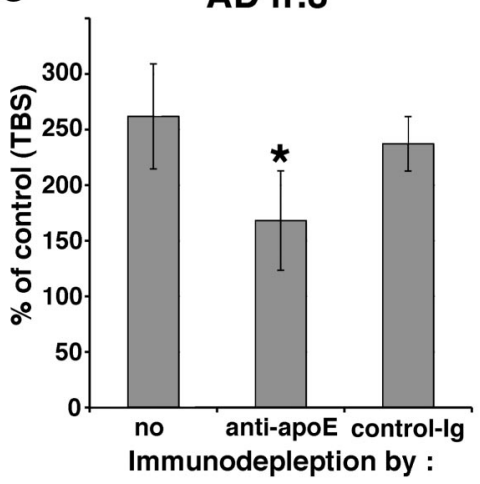

D

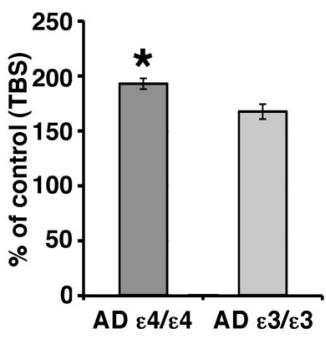

Figure 7. Endogenous apoE in the brain increases the level of $A \beta$ oligomers. $A, B$, Luminescence of SEC-separated fraction 6, 7, 8, or 9 from TBS-soluble fraction of $A D(\boldsymbol{A})$ or control $(\boldsymbol{B})$ brain incubated with split-luciferase-tagged $A \beta$ oligomers for $24 \mathrm{~h}$. An anti-apoE antibody revealed $36 \mathrm{kDa}$ apoE protein (bottom). C, Immunodepletion of fraction 8 of AD brains using no antibody, anti-apoE mAb $3 \mathrm{H} 1$ or control lg. Luminescence from immunodepleted fraction 8 of $A D$ brains incubated with split-luciferase-tagged $A \beta$ oligomers for $24 \mathrm{~h}$. Anti-apoE mAb $3 H 1$ significantly reduced the luminescence compared with control lg. $N=4$, average $\pm S D,{ }^{*} p<$ 0.05 , one-way ANOVA test (Bonferroni's test). $D$, Luminescence of SEC-separated fraction 8 from TBS-soluble fraction of 4 APOE $\varepsilon 4 / \varepsilon 4$ AD brains and 4 APOE $\varepsilon 3 / \varepsilon 3$ AD brains incubated with split-luciferase-tagged $A \beta$ oligomers for $24 \mathrm{~h}$. Fraction 8 from $A P O E \varepsilon 4 / \varepsilon 4$ AD brains significantly increased the level of $A \beta$ oligomers compared with that $A P O E \varepsilon 3 / \varepsilon 3$ AD brains. Average $\pm S D,{ }^{*} p<0.05$, one-way ANOVA test (Bonferroni's test).

\section{Discussion}

In this study, we demonstrate that the levels of $A \beta$ oligomers in TBS-soluble fraction of AD APOE $\varepsilon 4 / \varepsilon 4$ brains are 2.7-fold higher compared with $A P O E \varepsilon 3 / \varepsilon 3$ patient brains and 6.9 -fold higher compared with $A P O E \varepsilon 2 / \varepsilon x$ patient brains, whereas brains from non-demented controls had negligible levels of $A \beta$ oligomers (Fig. $1 A, B$ ). We also found that $\mathrm{A} \beta$ and apoE coeluted into HMW fractions in SEC-separated TBS-soluble fraction from AD brains, and coimmunoprecipitated (Fig. $2 B, C$ ), suggesting the possibility of an in vivo interaction between them. We confirmed that $\mathrm{A} \beta$ and apoE coeluted into HMW fractions in SEC-separated interstitial fluid from APP-PS mouse brains using a microdialysis techniques with a $1000 \mathrm{kDa}$ molecular weight cutoff membrane probe (S. Takeda, T. Hashimoto, and B. T. Hyman, unpublished observation), suggesting that the apoE and $\mathrm{A} \beta$ HMW complex endogenously exists in the brain and is not a product caused during the mechanical homogenization steps.

Based on these data, we hypothesized that apoE would facilitate $\mathrm{A} \beta$ oligomerization, and tested the idea that the extent of oligomer formation would be isoform dependent. We performed $\mathrm{A} \beta$ oligomerization assays using three different preparations of apoE. First, apoE on HDL particles, purified from conditioned media of immortalized astrocytes expressing human apoE2, apoE3, or apoE4, promoted the oligomerization of synthetic $A \beta$, splitluciferase-tagged $\mathrm{A} \beta$ oligomers, or LMW A $\beta$ isolated from TBS-soluble fraction of $A D$ patients' brains $A \beta$ (Fig. 3). Second, transient overexpression of apoE2, apoE3, or apoE4 in HEK293 cells stably expressing split-luciferase-tagged $\mathrm{A} \beta$ oligomers increased $\mathrm{A} \beta$ oligomers through apoE's C-terminal domain in an isoform-dependent manner (apoE2 < apoE3 < apoE4; Figs. 4, 6). Third, endogenous apoE extracted from TBS-soluble fraction of human $\mathrm{AD}$ and control brains also increased $\mathrm{A} \beta$ oligomers, again apoE3 $<$ apoE4 (Fig. 7). Similarly, we assessed oligomerization using two preparations: synthetic $\mathrm{A} \beta$ and a quantitative split-luciferase assay, with confirmatory results. apoE, especially apoE4, appears to enhance $\mathrm{A} \beta$ oligomers.

The current view of AD pathophysiology emphasizes the deleterious effects of $\mathrm{A} \beta$ oligomers on synapses, leading to synaptic dysfunction, and progressive memory impairment in $\mathrm{AD}$ patients (Lesné et al., 2006; Shankar et al., 2008; Li et al., 2009; Wu et al., 2010). Recently we found that apoE colocalized with $\mathrm{A} \beta$ oligomers at synapse in the brain of $\mathrm{AD}$ patient brains using an array tomographic technique and found that $A P O E \varepsilon 4 / \varepsilon 4 \mathrm{AD}$ patients have a significantly higher level of colocalization of apoE and $\mathrm{A} \beta$ oligomers at synapse compared with APOE $\varepsilon 3 / \varepsilon 3 \mathrm{AD}$ patients (Koffie et al., 2012). Our results suggest that apoE4 increases the level of $A \beta$ oligomers in the brain, leading to increased synaptic localization with $\mathrm{A} \beta$ oligomers, synaptic dysfunction, and hastening the development of cognitive impairments.

Biochemical analyses of human $\mathrm{AD}$ revealed that the level of TBS-soluble $\mathrm{A} \beta$ oligomers in APOE $\varepsilon 4 / \varepsilon 4$ brains are 2.7-fold higher compared with $\mathrm{AD} A P O E \varepsilon 3 / \varepsilon 3$ brains and 6.9 -fold higher compared with $\mathrm{AD} A P O E \varepsilon 2 / \varepsilon x$ brains (Fig. $1 A, B$ ). Importantly, these $\mathrm{AD}$ groups were matched for deposited amyloid burden. No significant correlation was observed between plaque burden and levels of TBS-soluble $\mathrm{A} \beta$ oligomers $(r=-0.01, p=$ 0.95 , Spearman's rank correlation test), so that the 2.7 -fold difference in the levels of TBS-soluble A $\beta$ oligomers between them cannot be attributed to the disruption of a higher amount of senile plaques in the APOE $\varepsilon 4 / \varepsilon 4$ group during the homogenization of the specimens. Thus, these results indicate that apoE influences both plaque burden and also the levels of TBS-soluble $\mathrm{A} \beta$ oligomers in an isoform-differential manner.

Using both synthetic $\mathrm{A} \beta$ (Fig. $3 A$ ) and a split-luciferase complementation assay (Figs. $3 C, 4$ ), we found that apoE increased $\mathrm{A} \beta$ oligomerization in an isoform-dependent manner (apoE2 $<$ apoE3 $<$ apoE4). Interestingly, experiments using deletion mutants of apoE demonstrate that the C-terminal domain of apoE is necessary and sufficient to drive $A \beta$ oligomerization, suggesting that apoE may directly interact with $A \beta$ oligomers through its C-terminal region (Fig. $6 B, D, E$ ). We also found that apoE4 enhanced the ratio of HMW $\mathrm{A} \beta$ oligomers compared with apoE2 or apoE3 (Fig. $4 E, F$ ), suggesting that $\mathrm{N}$-terminal domain might be important to modulate $\mathrm{A} \beta$ oligomerization. In a recent study using the anti-apoE $\mathrm{mAb} 3 \mathrm{H} 1$, which recognizes the amino acids 243-272, we observed significantly higher levels of apoE C-terminal fragments in APOE $\varepsilon 4 / \varepsilon 4 \mathrm{AD}$ brains compared with $A P O E \varepsilon 3 / \varepsilon 3 \mathrm{AD}$ brains. In addition, using in situ fluorescence lifetime imaging-fluorescent resonance energy transfer in human $\mathrm{AD}$ brain specimens, we found that $\mathrm{A} \beta$ is closer to the apoE $\mathrm{C}$-terminal region than to its $\mathrm{N}$-terminal region within doubly labeled senile plaques (Jones et al., 2011). Together, these results argue that not only full-length apoE4 but also C-terminal fragments of apoE4 containing the region at 243-272 amino-acid residues may additionally enhance the formation of $\mathrm{A} \beta$ oligomers in APOE $\varepsilon 4 / \varepsilon 4$ brains. Interestingly, the 243-272 aa residues of apoE are the major lipid-binding region of apoE, supporting 
the idea that apoE lipidation may be critical to facilitate $A \beta$ oligomer formation. We hypothesize that lipidated apoE might concentrate $\mathrm{A} \beta$ monomer and provide a scaffold for oligomerization of $A \beta$. Alternatively, we found lipidated apoE4 increased the level of synthetic $A \beta$ trimers and tetramers (Fig. $3 B$ ), suggesting that lipidated apoE, especially apoE4, might stabilize $\mathrm{A} \beta$ oligomers and inhibit the dissociation or further aggregation of $A \beta$. Furthermore, $A \beta$ oligomers may be able to escape from $A \beta$ degradation or phagocytosis by binding to apoE on HDL particles.

In addition to apoE, we found apoJ/clusterin and apoA-I, other apolipoproteins on the HDL particles, increased the level of $\mathrm{A} \beta$ oligomers (Fig. 5). Common variants in the apoJ/clusterin gene $(C L U)$ have recently been linked to an increased risk of developing AD (Harold et al., 2009; Lambert et al., 2009), and apoJ/clusterin-deficient mice crossed with APP-transgenic mice exhibit significantly fewer fibrillar $\mathrm{A} \beta$ deposits in the brain compared with APP-transgenic mice (DeMattos et al., 2002), suggesting that apoJ/clusterin may modify $\mathrm{A} \beta$ oligomer formation in the human brain similarly to apoE. By contrast, crossing apoA-Ideficient mice with APP-transgenic mice did not alter $\mathrm{A} \beta$ deposition in the brain (Fagan et al., 2004), indicating a small or no effect of apoA-I on $\mathrm{A} \beta$ oligomerization and fibrillization. We observed that apoA-I only slightly increased the levels of $A \beta$ oligomers (Fig. 5).

Recently, it was reported that the level of soluble oligomeric $A \beta$ in frontal cortex of young adults is higher than that of elderly people or Alzheimer' disease patients using ELISA experiments (van Helmond et al., 2010), potentially calling into question a relationship between oligomeric $\mathrm{A} \beta$ (as measured by the ELISA) with Alzheimer disease pathogenesis. In this study we observed that the level of HMW A $\beta$ from TBSsoluble fraction is under-estimated in ELISA experiments due to a possible masking effect either by itself or interacting molecules, and the treatment with $8 \mathrm{M}$ Guanidine- $\mathrm{HCl}$ increases the measured concentration of $\mathrm{A} \beta$ in HMW $\mathrm{A} \beta$ fractions using our specific ELISA conditions (Fig. $2 A$ ). It would be interesting to evaluate the age-dependent ELISA results in the context of these technical issues of $A \beta$ measurement.

In summary, we provide in vivo and in vitro evidence that apoE interacts with $\mathrm{A} \beta$ oligomers through its $\mathrm{C}$-terminal region and that apoE, particularly apoE4, promotes and stabilizes $\mathrm{A} \beta$ oligomerization. Given the relatively large magnitude of these effects (e.g., a 2.7-fold increase in $A \beta$ oligomers in $A P O E \varepsilon 4 / \varepsilon 4$ Alzheimer brains, compared with APOE E3/3 Alzheimer brains), it is plausible that these observations help explain the major risk for $\mathrm{AD}$ associated with $A P O E \varepsilon 4$ inheritance. Both the inhibition of the interaction between apoE and $\mathrm{A} \beta$ oligomers and the inhibition of the lipidation of apoE may be valuable therapeutic targets to prevent $\mathrm{A} \beta$ oligomerization and subsequent synaptic dysfunction.

\section{References}

Bu G (2009) Apolipoprotein E and its receptors in Alzheimer's disease: pathways, pathogenesis and therapy. Nat Rev Neurosci 10:333-344.

Castellano JM, Kim J, Stewart FR, Jiang H, DeMattos RB, Patterson BW, Fagan AM, Morris JC, Mawuenyega KG, Cruchaga C, Goate AM, Bales KR, Paul SM, Bateman RJ, Holtzman DM (2011) Human apoE isoforms differentially regulate brain amyloid- $\beta$ peptide clearance. Sci Transl Med 3:89ra57.

Chou CY, Lin YL, Huang LC, Sheu SY, Lin TH, Tsay HJ, Chang GG, Shiao MS (2005) Structural variation in human apolipoprotein E3 and E4: secondary structure, tertiary structure and size distribution. Biophys J 88:455466.

Corder EH, Saunders AM, Strittmatter WJ, Schmechel DE, Gaskell PC, Small GW, Roses AD, Haines JL, Pericak-Vance MA (1993) Gene dose of apo- lipoprotein E type 4 allele and the risk of Alzheimer's disease in late onset families. Science 261:921-923.

DeMattos RB, O’dell MA, Parsadanian M, Taylor JW, Harmony JAK, Bales KR, Paul SM, Aronow BJ, Holtzman DM (2002) Clusterin promotes amyloid plaque formation and critical for neuritic toxicity in a mouse model of Alzheimer's disease. Proc Natl Acad Sci U S A 99:10843-10848.

DeMattos RB, Cirrito JR, Parsadanian M, May PC, O’Dell MA, Taylor JW, Harmony JAK, Aronow BJ, Bales KR, Paul SM, Holtzman DM (2004) ApoE and clusterin cooperatively suppress $A \beta$ levels and deposition: evidence that apoE regulates extracellular $\mathrm{A} \beta$ metabolism in vivo. Neuron 41:193-202.

Dong LM, Wilson C, Wardell MR, Simmons T, Mahley RW, Weisgraber KH, Agard DA (1994) Human apolipoprotein E: Role of arginine 61 in mediating the lipoprotein preferences of the E3 and E4 isoforms. J Biol Chem 269:22358-22365.

Evans KC, Berger EP, Cho CG, Weisgraber KH, Lansbury PT Jr (1995) Apolipoprotein $\mathrm{E}$ is a kinetic but a thermodynamic inhibitor of amyloid formation: implications for the pathogenesis and treatment of Alzheimer disease. Proc Natl Acad Sci U S A 92:763-767.

Fagan AM, Watson M, Parsadanian M, Bales KR, Paul SM, Holtzman DM (2002) Human and murine ApoE markedly alters A beta metabolism before and after plaque formation in a mouse model of Alzheimer's disease. Neurobiol Dis 9:305-318.

Fagan AM, Christopher E, Taylor JW, Parsadanian M, Spinner M, Watson M, Fryer JD, Wahrle S, Bales KR, Paul SM, Holtzman DM (2004) ApoAI deficiency results in marked reductions in plasma cholesterol but no alterations in amyloid- $\beta$ pathology in a mouse model of Alzheimer's disease-like cerebral amyloidosis. Am J Pathol 165:1413-1422.

Gomez-Isla T, West HL, Rebeck GW, Harr SD, Growdon JH, Locascio JJ, Perls TT, Lipsitz LA, Hyman BT (1996) Clinical and pathological correlates of apolipoprotein E $\varepsilon 4$ in Alzheimer's disease. Ann Neurol 39:62-70.

Harold D, Abraham R, Hollingworth P, Sims R, Gerrish A, Hamshere ML, Pahwa JS, Moskvina V, Dowzell K, Williams A, Jones N, Thomas C, Stretton A, Morgan AR, Lovestone S, Powell J, Proitsi P, Lupton MK, Brayne C, Rubinsztein DC, et al. (2009) Genome-wide association study identifies variants at CLU and PICALM associated with Alzheimer's disease. Nat Genet 41:1088-1093.

Hashimoto T, Wakabayashi T, Watanabe A, Kowa H, Hosoda R, Nakamura A, Kanazawa I, Arai T, Takio K, Mann DM, Iwatsubo T (2002) CLAC: a novel Alzheimer amyloid plaque component derived from a transmembrane precursor, CLAC-P/collagen type XXV. EMBO J 21:1524-1534.

Hashimoto T, Adams KW, Fan Z, McLean PJ, Hyman BT (2011) Characterization of oligomer formation of amyloid- $\beta$ peptide using a splitluciferase complementation assay. J Biol Chem 286:27081-27091.

Hatters DM, Peters-Libeu CA, Weisgraber KH (2006) Apolipoprotein E structure: insights into function. Trends Biochem Sci 31:445-454.

Holtzman DM, Bales KR, Tenkova T, Fagan AM, Parsadanian M, Sartorius LJ, Mackey B, Olney J, McKeel D, Wozniak D, Paul SM (2000) Apolipoprotein $\mathrm{E}$ isoform-dependent amyloid deposition and neuritic degeneration in a mouse model of Alzheimer's disease. Proc Natl Acad Sci U S A 97:2892-2897.

Holtzman DM, Morris JC, Goate AM (2011) Alzheimer's disease: the Challenge of the second century. Sci Transl Med 3:77sr1.

Hori Y, Hashimoto T, Wakutani Y, Urakami K, Nakashima K, Condron MM, Tsubuki S, Saido TC, Teplow DB, Iwatsubo T (2007) Tottori (D7N) and English (H6R) familial Alzheimer disease mutations accelerate A $\beta$ fibril formation without increasing protofibril formation. J Biol Chem 282: 4916-4923.

Ingelsson M, Fukumoto H, Newell KL, Growdon JH, Hedley-Whyte ET, Frosch MP, Albert MS, Hyman BT, Irizarry MC (2004) Early A $\beta$ Accumulation and progressive synaptic loss, gliosis, and tangle formation in AD brain. Neurology 62:925-931.

Jones PB, Adams KW, Rozkalne A, Spires-Jones TL, Hshieh TT, Hashimoto T, von Armin CAF, Mielke M, Bacskai BJ, Hyman BT (2011) Apolipoprotein $\mathrm{E}$ : isoform specific differences in tertiary structure and interaction with amyloid- $\beta$ in human Alzheimer brain. PLoS One 6:e14586.

Koffie RM, Meyer-Luehmann M, Hashimoto T, Adams KW, Mielke ML, Garcia-Alloza M, Micheva KD, Smith SJ, Kim ML, Lee VMY, Hyman BT, Spires-Jones TL (2009) Oligomeric amyloid $\beta$ associates with postsynaptic densities and correlates with excitatory synapse loss near senile plaques. Proc Natl Acad Sci U S A 106: 4012-4017.

Koffie RM, Hashimoto T, Tai HC, Kay KR, Serrano-Pozo A, Joyner D, Hou S, 
Kopeikina KJ, Frosch MP, Lee VMY, Holtzman DM, Hyman BT, SpiresJones TL (2012) Apolipoprotein E4 effects in Alzheimer disease are mediated by synaptotoxic oligomeric amyloid- $\beta$. Brain 135:2155-2168.

LaDu MJ, Falduto MT, Manelli AM, Reardon CA, Getz GS, Frail DE (1994) Isoform-specific binding of apolipoprotein $\mathrm{E}$ to $\beta$-amyloid. J Biol Chem 269:23403-23406.

LaDu MJ, Stine WB Jr, Narita M, Getz GS, Reardon CA, Bu G (2006) Selfassembly of HEK cell-secreted apoE particles resembles apoE enrichment of lipoproteins as a ligand for the LDL receptor-related protein. Biochemistry $45: 381-390$.

Lambert JC, Heath S, Even G, Campion D, Sleegers K, Hiltunen M, Combarros O, Zelenika D, Bullido MJ, Tavernier B, Letenneur L, Bettens K, Berr C, Pasquier F, Fiévet N, Barberger-Gateau P, Engelborghs S, De Deyn P, Mateo I, Franck A, et al. (2009) Genome-wide association study identifies variants at $C L U$ and $C R 1$ associated with Alzheimer's disease. Nat Genet 41:1094-1099.

Lesné S, Koh MT, Kotilinek L, Kayed R, Glabe CG, Yang A, Gallagher M, Ashe $\mathrm{KH}$ (2006) A specific amyloid- $\beta$ protein assembly in the brain impairs memory. Nature 440:352-357.

Li S, Hong S, Shepardson NE, Walsh DM, Shankar GM, Selkoe D (2009) Soluble oligomers of amyloid $\beta$ protein facilitate hippocampal long-term depression by disrupting neuronal glutamate uptake. Neuron 62:788801.

Mahley RW, Weisgraber KH, Huang Y (2009) Apolipoprotein E: structure determines function, from atherosclerosis to Alzheimer's disease to AIDS. J Lipid Res 50:S183-S188.

Morikawa M, Fryer JD, Sullivan PM, Christopher EA, Wahrle SE, DeMattos RB, O'Dell MA, Fagan AM, Lashuel HA, Walz T, Asai K, Holtzman DM (2005) Production and characterization of astrocyte-derived human apolipoprotein $\mathrm{E}$ isoforms from immortalized astrocytes and their interactions with amyloid- $\beta$. Neurobiol Dis 19:66-76.

Naiki H, Gejyo F, Nakakuki K (1997) Concentration-dependent inhibitory effects of apolipoprotein $\mathrm{E}$ on Alzheimer's $\beta$-amyloid fibril formation in vitro. Biochemistry 36:6243-6250.

Näslund J, Thyberg J, Tjernberg LO, Wernstedt C, Karlström AR, Bogdanovic N, Gandy SE, Lannfelt L, Terenius L, Nordstedt C (1995) Characterization of stable complexes involving apolipoprotein $\mathrm{E}$ and the amyloid $\beta$ peptide in Alzheimer's disease brain. Neuron 15:219-228.

Rebeck GW, Reiter JS, Strickland DK, Hyman BT (1993) Apolipoprotein E in sporadic Alzheimer's disease: allelic variation and receptor interactions. Neuron 11:575-580.

Riddell DR, Zhou H, Atchison K, Warwick HK, Atkinson PJ, Jefferson J, Xu L, Aschmies S, Kirksey Y, Hu Y, Wagner E, Parratt A, Xu J, Li Z, Zaleska MM,
Jacobsen JS, Pangalos MN, Reinhart PH (2008) Impact of apolipoprotein E (ApoE) polymorphism on brain apoE levels. J Neurosci $28: 11445-11453$.

Selkoe DJ (2001) Alzheimer's disease: genes, proteins and therapy. Physiol Rev 81:741-766.

Shankar GM, Li S, Mehta TH, Garcia-Munoz A, Shepardson NE, Smith I, Brett FM, Farrell MA, Rowan MJ, Lemere CA, Regan CM, Walsh DM, Sabatini BL, Selkoe DJ (2008) Amyloid- $\beta$-protein dimers isolated directly from Alzheimer's brains impair synaptic plasticity and memory. Nat Med 14:837-842.

Strittmatter WJ, Saunders AM, Schmechel D, Pericak-Vance M, Enghild J, Salvesen GS, Roses AD (1993a) Apolipoprotein E: high-avidity binding to $\beta$-amyloid and increased frequency of type 4 allele in late-onset familial Alzheimer disease. Proc Natl Acad Sci U S A 90:1977-1981.

Strittmatter WJ, Weisgraber KH, Huang DY, Dong LM, Salvesen GS, PericakVance M, Schmechel D, Saunders AM, Goldgaber D, Roses AD (1993b) Binding of human apolipoprotein $\mathrm{E}$ to synthetic amyloid $\beta$ peptide: isoform-specific effects and implication for late-onset Alzheimer disease. Proc Natl Acad Sci U S A 90:8098-8102.

Townsend M, Shankar GM, Mehta T, Walsh DM, Selkoe DJ (2006) Effects of secreted oligomers of amyloid $\beta$-protein on hippocampal synaptic plasticity: a potent role for trimers. J Physiol 572:477-492.

van Helmond Z, Miners JS, Kehoe PG, Love S (2010) Higher soluble amyloid $\beta$ concentration in frontal cortex of young adults than in normal elderly or Alzheimer's disease. Brain Pathol 20:787-793.

Wu HY, Hudry E, Hashimoto T, Kuchibhotla K, Rozkalne A, Fan Z, SpiresJones TL, Xie H, Arbel-Ornath M, Grosskreutz CL, Bacskai BJ, Hyman BT (2010) Amyloid $\beta$ induces the morphological neurodegenerative triad of spine loss, dendritic simplification, and neuritic dystrophies through calcineurin activation. J Neurosci 30:2636-2649.

Yamada K, Yabuki C, Schubert P, Schenk D, Hori Y, Ohtshuki S, Terasaki T, Hashimoto T Iwatsubo T (2009) A $\beta$ immunotherapy: Intracerebral sequestration of $\mathrm{A} \beta$ by an anti- $\mathrm{A} \beta$ monoclonal antibody 266 with high affinity to soluble $A \beta$. J Neurosci 29:11393-11398.

Ye S, Huang Y, Müllendorff K, Dong L, Giedt G, Meng EC, Cohen FE, Kuntz ID, Weisgraber KH, Mahley RW (2005) Apolipoprotein (apo) E4 enhances amyloid $\beta$ peptide production in cultured neuronal cells: ApoE structure as a potential therapeutic target. Proc Natl Acad Sci U S A 102:18700-18705.

Zannis VI, Breslow JL, Utermann G, Mahley RW, Weisgraber KH, Havel RJ, Goldstein JL, Brown MS, Schonfeld G, Hazzard WR, Blum C (1982) Proposed nomenclature of apoE isoproteins, apoE genotypes, and phenotypes. J Lipid Res 23:911-914. 